\title{
Characterisation of dust aerosols in the infrared from IASI and comparison with PARASOL, MODIS, MISR, CALIOP, and AERONET observations
}

\author{
S. Peyridieu ${ }^{1, *}$, A. Chédin ${ }^{1}$, V. Capelle ${ }^{1}$, C. Tsamalis ${ }^{1}$, C. Pierangelo ${ }^{2}$, R. Armante ${ }^{1}$, C. Crevoisier ${ }^{1}$, L. Crépeau ${ }^{1}$, \\ M. Siméon ${ }^{1}$, F. Ducos ${ }^{3}$, and N. A. Scott ${ }^{1}$ \\ ${ }^{1}$ Laboratoire de Météorologie Dynamique, UMR8539, CNRS/IPSL, Ecole Polytechnique, Palaiseau, France \\ ${ }^{2}$ Centre National d'Etudes Spatiales, Toulouse, France \\ ${ }^{3}$ Laboratoire d'Optique Atmosphérique, Université des Sciences et Technologies de Lille, Villeneuve d'Ascq, France \\ *now at: M3 Systems c/o CLS, Space Oceanography Division, Ramonville-St-Agne, France \\ Correspondence to: V. Capelle (virginie.capelle@lmd.polytechnique.fr)
}

Received: 10 August 2012 - Published in Atmos. Chem. Phys. Discuss.: 6 September 2012

Revised: 8 May 2013 - Accepted: 23 May 2013 - Published: 25 June 2013

\begin{abstract}
Infrared Atmospheric Sounder Interferometer (IASI) observations covering the period from July 2007 to December 2011 are interpreted in terms of monthly mean, $1^{\circ} \times 1^{\circ}, 10 \mu \mathrm{m}$ dust Aerosol Optical Depth (AOD), mean altitude and coarse mode effective radius. The geographical study area includes the northern tropical Atlantic and the northwest Arabian Sea, both characterised by strong, regular dust events. The method developed relies on the construction of Look-Up-Tables computed for a large selection of atmospheric situations and observing conditions. At a regional scale, a good agreement is found between IASI-retrieved $10 \mu \mathrm{m}$ AOD and total visible optical depth at $550 \mathrm{~nm}$ from either the Moderate resolution Imaging Spectroradiometer (MODIS/Aqua or Terra), or the Multi-angle Imaging SpectroRadiometer (MISR), or the Polarization and Anisotropy of Reflectances for Atmospheric Science coupled with Observations from a Lidar (PARASOL). Taking into account the ratio existing between infrared and visible AODs, the diversity between the different $550 \mathrm{~nm}$ AODs is similar to the difference between these and the IASI AODs. The infrared AOD to visible AOD ratio, partly reflecting the varying distribution of the dust layer between the dust coarse mode particles seen by IASI, and the fine mode seen by the other instruments, is found to vary with the region observed with values close to already published values. Comparisons between the climatologies of the $10 \mu \mathrm{m}$ IASI AOD and of the PARASOL non-spherical coarse mode AOD at
\end{abstract}

$865 \mathrm{~nm}$, both expected to be representative of the dust coarse mode, lead to conclusions differing according to the region considered. These differences are discussed in the light of the MODIS Angström exponent $(865-550 \mathrm{~nm})$. At local scale, around six Aerosol Robotic Network (AERONET) sites, close or far from the dust sources, a similar satisfactory agreement is found between IASI and the visible AODs and the differences between these products are shown and analysed. IASI-retrieved dust layer mean altitudes also compare well with the Cloud-Aerosol Lidar with Orthogonal Polarization (CALIOP/CALIPSO) aerosol mean layer altitude, both in terms of climatology and of zonal evolution throughout the Atlantic. Comparisons between the IASI-retrieved dust coarse mode effective radius and retrievals from AERONET at the six sites brings into evidence an almost systematic bias of about $+0.35 \mu \mathrm{m}$ (IASI-AERONET). Removing this bias leads to a satisfactory agreement between the climatologies of these two products. Overall, these results illustrate the dust westward transport characterised by a fast decrease of the dust optical depth, a somewhat slower decrease of the altitude, and an effective radius remaining almost constant during summer throughout the northern tropical Atlantic. They also demonstrate the capability of high resolution infrared sounders to contribute improving our understanding of processes related to the aerosols (transport, sources, cycles, effect of aerosols on the terrestrial radiation, etc.). 


\section{Introduction}

Aerosols originate either from natural sources (dust, volcanic, sea salt aerosols, etc.) or from anthropogenic sources (smoke, sulfates, soot, etc.). In its fourth report, the Intergovernmental Panel on Climate Change (IPCC, 2007) notes that, if aerosol forcings are now better understood than at the time of the Third Assessment Report due to improved measurements and more comprehensive modelling, they remain the dominant uncertainty in radiative forcing, on the one hand because they show a very high spatio-temporal variability, on the other because they influence many complex processes of the planet. Amongst all aerosol species, mineral dust is a major contributor to total aerosol loading and has been the subject of an increasing number of studies (e.g. Maher et al., 2010; Mahowald et al., 2010; Formenti et al., 2011; Shao et al., 2011; Knippertz et al., 2012). Remote sensing in the visible domain has been widely used to obtain better characterisation of these particles and their effect on solar radiation. After a long period of relative disinterest in aerosol remote sensing in the infrared (one of the oldest reference is by Legrand et al. (1989) using the low spectral resolution, one window-channel, radiometer on board Meteosat), a marked growing interest in the infrared is now observed with the emergence of hyperspectral instruments as AIRS and IASI (Pierangelo et al., 2004, 2005; De Souza-Machado, 2006; Klüser et al., 2011, 2012). Indeed, from infrared remote sensing a coherent ensemble of aerosol characteristics can be retrieved simultaneously: AOD, mean altitude and size; this allows the impact of aerosols on terrestrial radiation to be quantified. Moreover, infrared and visible spectra are not sensitive to the same ranges of particle size: the coarse mode (size range $>1 \mu \mathrm{m}$ ) is preferentially observed in the infrared, whereas the fine mode $(<1 \mu \mathrm{m})$ is mostly observed in the visible.

The new generation of high spectral resolution infrared sounders, such as the Atmospheric Infrared Sounder (AIRS) on Aqua, or the Infrared Atmospheric Sounder Interferometer (IASI) on Metop, have already shown promising capabilities to retrieve dust aerosol properties such as the $10 \mu \mathrm{m}$ optical depth, the mean altitude, and the mean coarse mode particle size (Pierangelo et al., 2004, 2005; Peyridieu et al., 2010, hereafter referred to as "Pey2010").

In this study, dust aerosol characteristics are retrieved from a method based on a Look-Up-Table (LUT) approach, already applied to more than $9 \mathrm{yr}$ of AIRS observations (Pey2010), with results being obtained at a space-time resolution of 1 degree- 1 month. Two spectral bands are of particular interest for the retrieval of aerosol properties in the infrared: between 8 and 12 microns, where channels are sensitive to both the dust optical depth and the altitude of the dust layer, and around 4 microns, where channels are essentially sensitive to the dust optical depth (Pierangelo et al., 2004; Pey2010: see their Fig. 1). Combining channels from these two spectral regions allows simultaneous retrieval of both properties. Retrieval of the dust coarse mode aerosol effective radius, a variable of prime importance for the study of dust radiative forcing, transport and deposition, uses a channel at about $9.3 \mu \mathrm{m}$ (Pierangelo et al., 2005) selected for its high sensitivity to dust size and relative insensitivity to other atmospheric components (ozone, sulfates) or to dust asphericity.

This method is applied here to Infrared Atmospheric Sounder Interferometer (IASI) observations for the period from July 2007 to December 2011. Compared to AIRS, IASI has the advantage of a higher spectral resolution $\left(0.50 \mathrm{~cm}^{-1}\right.$ apodized), being constant throughout the whole spectrum, and of a full coverage of the spectral domain, allowing the selection of channels more specific to the variable considered. Its drawback is a larger noise at short wavelengths which may be overcome by averaging a few adjacent and radiatively similar channels.

Data and method are described in Sect. 2. Section 3 presents the results from IASI and comparisons with other aerosol products. For the AOD, these products are derived from the Moderate Resolution Imaging Spectro-radiometer (MODIS/Aqua and Terra), from the Multi-angle Imaging SpectroRadiometer (MISR), from the Polarization and Anisotropy of Reflectances for Atmospheric Science coupled with Observations from a Lidar (PARASOL), and from the AErosol RObotic NETwork (AERONET). For the altitude, comparisons are done with the Cloud-Aerosol Lidar with Orthogonal Polarization (CALIOP/CALIPSO). Finally, the radius is compared with AERONET coarse mode radius. These results are discussed in Sect. 4.

\section{Method and data}

\subsection{Method}

The method for the retrieval of dust characteristics from IASI observations was originally developed for application to AIRS (Pierangelo et al., 2004). The present study uses a slightly modified version of this method already described in detail in Pey2010. It is a three-step algorithm based on a "Look-Up-Table" (LUT) approach. The two first steps, determination of the atmospheric state observed (using six IASI channels) and simultaneous determination of the $10 \mu \mathrm{m}$ AOD and aerosol layer mean altitude (using eight IASI channels), have been described in Pey2010. The third step of the algorithm is the retrieval of the dust coarse mode effective radius $\left(R_{\text {eff }}\right)$ : the approach follows the one described in Pierangelo et al. (2005). Here, it must be recalled that in the thermal infrared, at the reference $10 \mu \mathrm{m}$ wavelength, the number of parameters describing the Particle Size Distribution (PSD) can be reduced to one: the effective radius $R_{\text {eff }}$ (Pierangelo et al., 2005). In fact, the PSD may be considered as being monomodal and the impact of its width is negligible once the AOD is given. "Radius-LUT" are built for a channel 

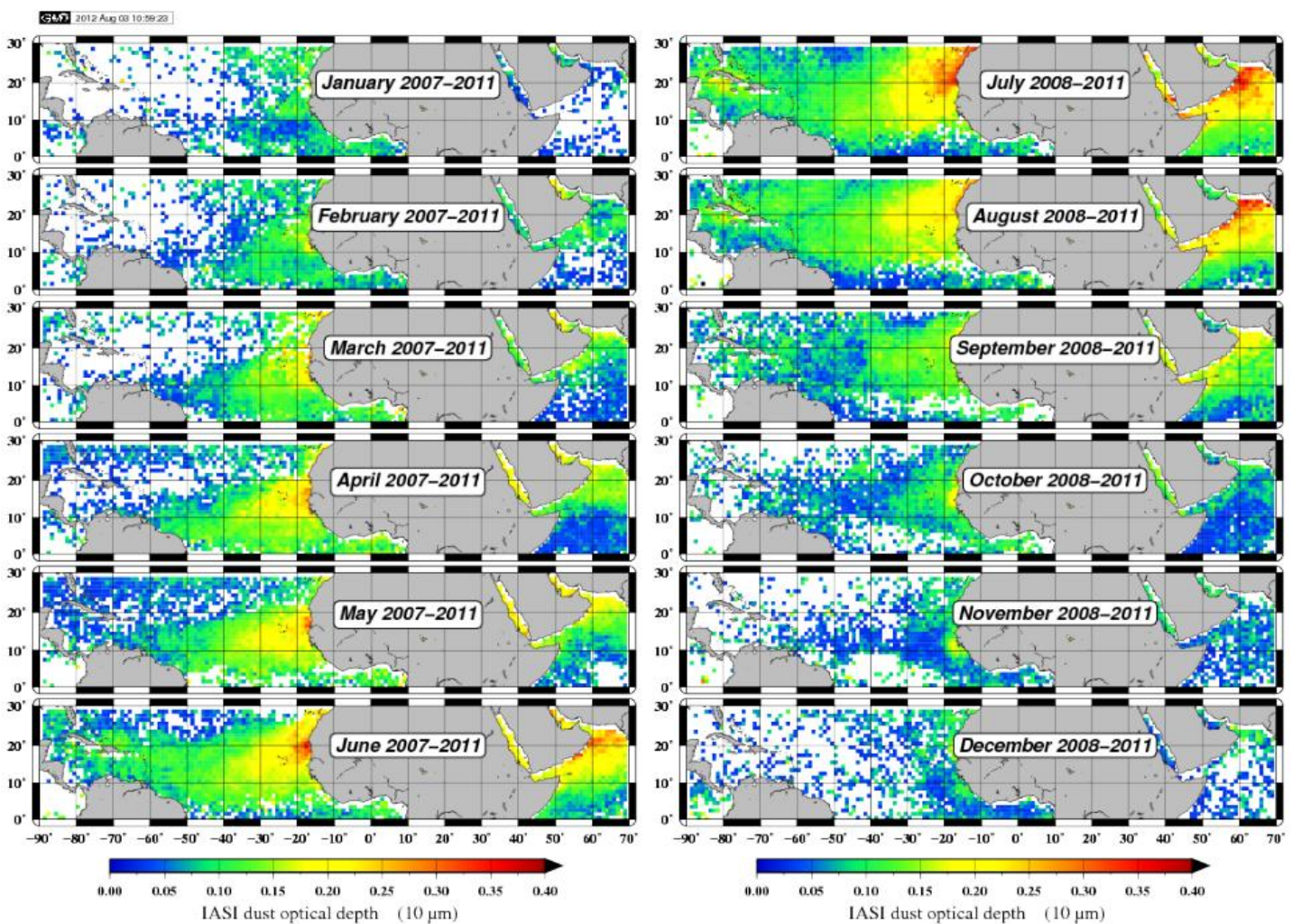

Fig. 1a. IASI-retrieved $10 \mu \mathrm{m}$ AOD climatology. Average is performed over $4 \mathrm{yr}$ for January to June and over $5 \mathrm{yr}$ from July to December.
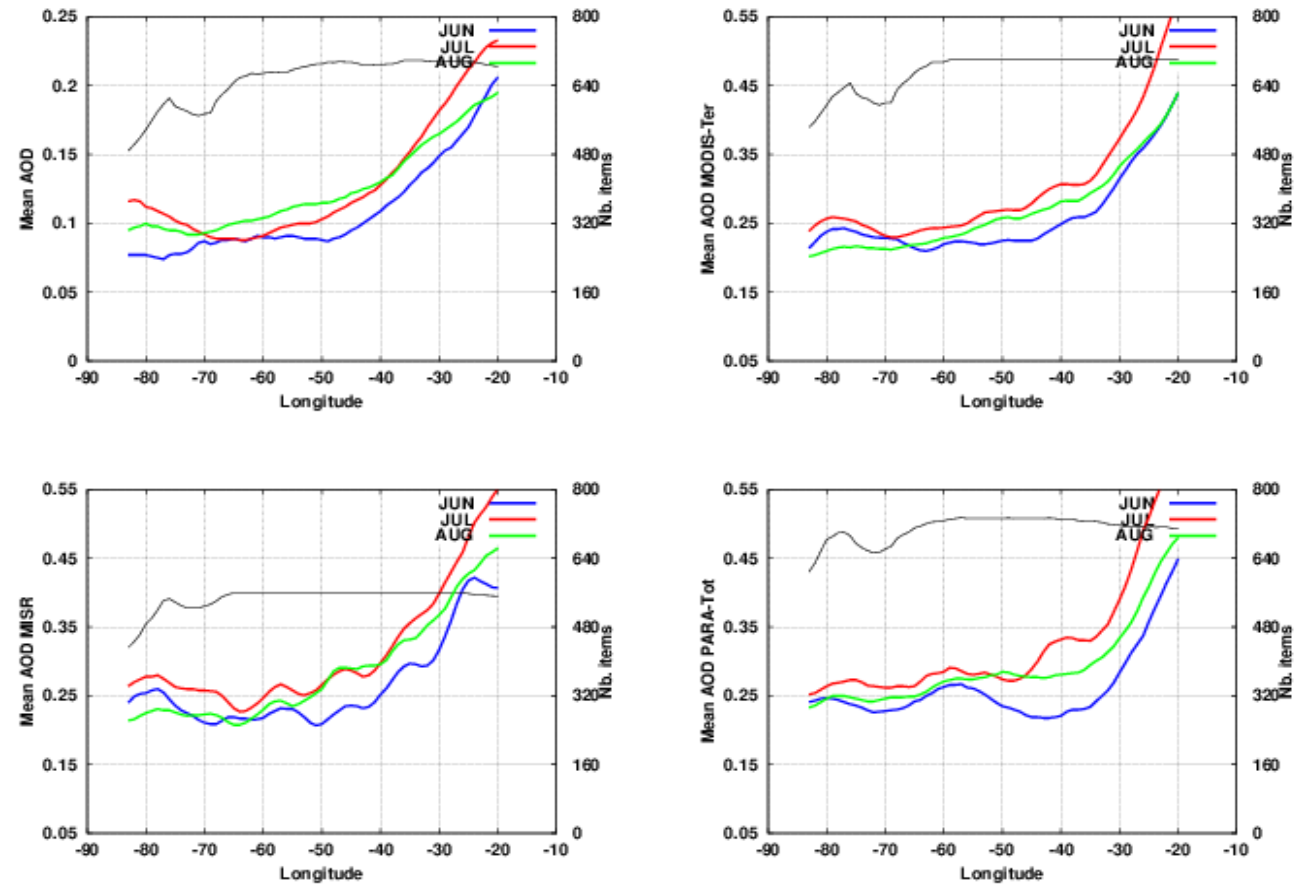

Fig. 1b. 2007-2011 averaged zonal evolution of the IASI AOD (top-left), the MODIS (Terra) AOD (top right), the MISR AOD (bottom left), and the PARASOL AOD (bottom-right), from the African coast to the Caribbean, in June (blue), July (red), and August (green). Data are averaged over the latitude band $10^{\circ} \mathrm{N}-30^{\circ} \mathrm{N}$ and over $\pm 3^{\circ}$ longitude, around the longitude considered. Black solid line: number of items for July (right ordinate). 
Table 1. Entries used to build the IASI Look-Up-Tables (LUT) of simulated brightness temperatures (BTs) used in the three-step algorithm. BTs for bold-faced values are calculated using the forward coupled radiative transfer model 4AOP-DISORT, BTs for the other values are interpolated (linearly or quadratically).

\begin{tabular}{|c|c|c|c|}
\hline & $\begin{array}{l}\text { step } 1: \text { LUT - } \\
\text { Atmosphere }\end{array}$ & $\begin{array}{l}\text { step } 2 \text { : LUT - } \\
\text { AOD, altitude }\end{array}$ & $\begin{array}{l}\text { step 3: LUT - } \\
\text { effective radius }\end{array}$ \\
\hline Number of IASI channels & 6 & 8 & 1 \\
\hline Angles $\left(^{\circ}\right)$ & $\begin{array}{l}\mathbf{0}, 5,10,15,20,25 \\
30,35,40,45,50\end{array}$ & $\begin{array}{l}0,5,10, \mathbf{1 5}, 20,25, \mathbf{3 0}, \mathbf{3 5} \\
40,45,50\end{array}$ & $\mathbf{0}, 5,10, \mathbf{1 5}, 20,25, \mathbf{3 0}$ \\
\hline AOD values & N/A & $\begin{array}{l}\mathbf{0 . 0}, 0.1,0.2,0.3, \mathbf{0 . 4} \\
0.5,0.6,0.7, \mathbf{0 . 8}\end{array}$ & $\begin{array}{l}\mathbf{0 . 1}, 0.2,0.3, \mathbf{0 . 4} \\
0.5,0.6,0.7, \mathbf{0 . 8}\end{array}$ \\
\hline Altitude values (m) & N/A & $\begin{array}{l}757,1258,1756,2411 \\
3254,4116,4965,5795\end{array}$ & $\begin{array}{l}\text { 757, 1258, 1756, } 2411 \\
3254,4116,4965,5795\end{array}$ \\
\hline Radii values $(\mu \mathrm{m})$ & N/A & $\begin{array}{l}2.3\left(R_{\text {eff }}\right) \text { or } 3.0\left(r_{\operatorname{modV}}\right) \\
\text { OPAC/MITR }\end{array}$ & $\begin{array}{l}\mathbf{0 . 5}, 0.8, \mathbf{1 . 0}, \mathbf{1 . 5}, \mathbf{2 . 0}, \\
2.5, \mathbf{3 . 0}, 4.0, \mathbf{5 . 0}\end{array}$ \\
\hline
\end{tabular}

selected at $9.315 \mu \mathrm{m}$ and for the values of the dust infrared optical depth, mean altitude and $R_{\text {eff }}$ of Table 1 , using a monomodal lognormal size distribution. In order to simulate IASI brightness temperatures (BT) for the different effective radii, the optical properties were calculated using a Mie code (Mishchenko et al., 2002 and ftp://ftp.giss.nasa.gov/ pub/crmim/spher.f) and the refractive indices of the "Mineral Transported" (MITR) aerosol model from the "Optical Properties of Clouds and Aerosols" (OPAC) database (Hess et al., 1998). For this model, the complex refractive index at $550 \mathrm{~nm}$ is $1.53+0.0055 \mathrm{i}$ and the mode radius is $0.5 \mu \mathrm{m}$. Using the atmospheric and aerosol properties (AOD, altitude) retrieved from the two first steps, the observed BT of the IASI radiussensitive channel selected is compared to the LUT-simulated BTs for all sampled $R_{\text {eff }}$ values and the two values framing the observed BT are kept. The retrieved $R_{\text {eff }}$ value results from a linear interpolation between their associated $R_{\text {eff }}$ values.

Entries used to build the IASI simulated brightness temperature LUTs used in the three-step algorithm are given in Table 1. In this Table, the entries in bold face correspond to LUTs BTs calculated using the forward coupled radiative transfer model 4A/OP-DISORT (Scott and Chédin, 1981; Stamnes et al., 1988, http://4aop.noveltis.com). The other entries correspond to LUTs BTs interpolated linearly or quadratically.

Several aspects of the retrieval algorithm such as the robustness to aerosol model (size distribution, shape, and refractive index), the possible contamination by other aerosol species, the radiative transfer model bias removal, or the cloud mask including discrimination between clouds and aerosols, etc., were investigated in Pierangelo et al. (2004) and Pey2010. Most of the methodological work developed here has consisted in the adaptation to IASI of the AIRS channels selection procedure.

\subsection{Data}

In addition to IASI, the core instrument of this study, several other space-based instruments and their aerosol products have been used for the purpose of comparison and validation: MODIS, MISR and PARASOL, all measuring visible AOD and, therefore essentially sensitive to the fine mode. CALIOP, which is also part of the A-train, provides a measure of the aerosol vertical distribution.

Developed by CNES in collaboration with EUMETSAT, the IASI instrument (Chalon et al., 2001; http://smsc.cnes. fr/IASI), onboard the MetOp-A polar platform, is a Fourier Transform Spectrometer that measures Earth-emitted infrared radiation. Launched in October 2006 (operational since July 2007), it provides 8461 spectral channels, between $15.5 \mu \mathrm{m}$ and $3.63 \mu \mathrm{m}$, with a spectral resolution of $0.50 \mathrm{~cm}^{-1}$ after apodisation and a regular spectral sampling interval of $0.25 \mathrm{~cm}^{-1}$. Metop-A crosses the Equator at 9:30 p.m. on its ascending node. IASI provides a near global coverage twice a day at a spatial resolution of $12 \mathrm{~km}$ at nadir.

MODIS (http://modis.gsfc.nasa.gov/) is an imaging radiometer flying on board the Terra platform since December 1999 and on board the Aqua platform since May 2002. Its data products are widely used in the aerosol community (Tanré et al., 1997; Remer et al., 2005, 2008). Aqua (Terra) crosses the Equator at 01:30 a.m. (10:30 a.m.) on its descending node. Aqua (Terra) crosses the Equator at 01:30 a.m. (10:30 a.m.) on its descending node. This temporal shift with IASI is not significant at the monthly scale. Here, we use the Level 3 monthly products (total and fine mode) from Terra, which provide the optical depth reported at $550 \mathrm{~nm}$ at a spatial resolution of $1^{\circ} \times 1^{\circ}$ (see: http://disc.sci.gsfc.nasa. gov/giovanni/overview/index.html). MODIS fine mode AOD is obtained by multiplying the total AOD by the fine mode fraction. We have verified that no significant differences are observed between Terra and Aqua, at least at the monthly scale considered here. 
MISR (http://www-misr.jpl.nasa.gov; Diner et al., 2002), flying on board the Terra platform since December 1999, views the sunlit Earth simultaneously at nine widely spaced angles. The MISR Level 3 global data products are reported on a rectangular grid $0.5^{\circ}$ by $0.5^{\circ}$ degree. Here, use is made of the AOD reported at $555 \mathrm{~nm}$.

Launched in December 2004, PARASOL carries a POLDER-like (Polarization and Directionality of the Earth's Reflectances) wide field radiometer. The instrument (Deschamps et al., 1994) measures the polarized light in different directions for retrieving aerosol and cloud optical and physical properties (Tanré et al., 2011). The mission takes also advantage of the other instruments in the A-Train formation. Original AOD values are given at $865 \mathrm{~nm}$ in the official PARASOL archive provided by the ICARE datacenter (http://www.icare.univ-lille1.fr/). They are here referenced to $550 \mathrm{~nm}$ using the Angström exponent (865-670) from the Level 2 products (orbits) of the PARASOL archive, then combined into global, monthly products, gridded at a resolution of 0.25 degree. Use is also made of the non-spherical coarse mode (NSCM) monthly mean AOD at $865 \mathrm{~nm}$.

Launched in April 2006, the satellite CALIPSO with the on board two-wavelength depolarization lidar CALIOP permits an accurate determination of the aerosol altitude (Winker et al., 2007, 2009; Kim et al., 2008). The depolarization at $532 \mathrm{~nm}$ allows discriminating between the dust aerosols and other types of aerosols which in general do not depolarize light. It should be noted that CALIPSO, a nearnadir viewing instrument, does not offer a full coverage of the Earth (beam diameter of $70 \mathrm{~m}$ at the Earth's surface, 16 days repetition cycle) which makes it difficult to statistically interpret the result. Here, the $\mathrm{L} 25 \mathrm{~km}$ aerosol layer product (version 3.01) is used to calculate monthly mean altitudes at regional scale. Two classes of aerosols are used for the comparison of the IASI altitude with the L2 product: "dust" and "polluted dust". The polluted dust class, which corresponds to dust mixed with other types of aerosols, as biomass burning or urban pollution, is also taken into account. For one CALIOP measurement, up to eight aerosol layers can be reported. With the purpose of a simple and robust evaluation of IASI retrievals, only the cases where one aerosol layer is detected and measured by the lidar are selected. The subset of CALIOP data resulting from this selection represents about $65 \%$ of all CALIOP data where aerosol layers are detected (see Pey2010 for more details). Contrary to CALIOP, the IASI dust retrieval algorithm outputs the mean altitude of the whole dust layer, i.e. the altitude at which half of the AOD is below and half of the AOD is above, with low sensitivity to a complex layering of the dust.

Finally, IASI-retrieved $10 \mu \mathrm{m}$ AOD and coarse mode effective radius are compared to AERONET (see, for example, Dubovik et al., 2002) visible AOD (550 nm) and coarse mode radius for several sites of the northern tropical Atlantic and one site of the Arabian Sea.

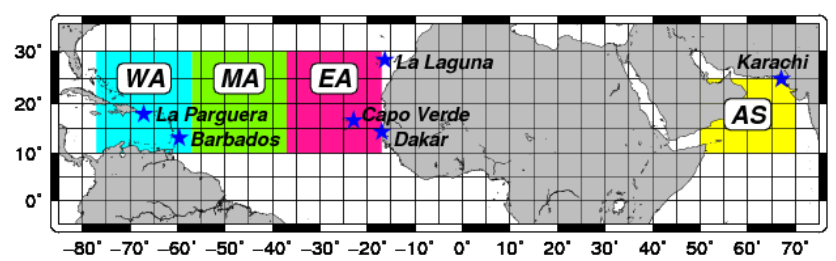

Fig. 2. Boundaries of the four regions of study: EA: East Atlantic, MA: Mid-Atlantic, WA: West Atlantic, AS: Arabian Sea. Blue stars indicate the locations of the AERONET sites considered.

\section{Results}

The period analysed extends from the beginning of IASI operational activity (July 2007) to December 2011. Results are presented for the northern tropics of the Atlantic Ocean and northwest Arabian Sea. Only night-time observations are analysed because of the use of shortwave channels significantly sensitive to sun radiation.

\subsection{IASI $10 \mu \mathrm{m}$ optical depth $1^{\circ} \times 1^{\circ}$ climatology}

Figure 1a shows IASI-retrieved monthly climatology $\left(1^{\circ} \times\right.$ $1^{\circ}$ ) of the dust aerosol mean $10 \mu \mathrm{m}$ optical depth for the period 07/2007-12/2011. Blank areas correspond to cloudy conditions or no retrievals. This figure clearly shows dust transport, through the so-called Saharan Air Layer (SAL), from the Saharan sources to the Caribbean and North America in summer and to the Amazon basin in winter as already described in several publications (see, for example, Chiapello et al., 1995, 2005; Karyampudi et al., 1999; Kaufman et al., 2005; Huang et al., 2010). Note the "clean" period in November-December as shown in Ben-Ami et al. (2012). Figure 1a is similar to the AIRS climatology of Pey2010 as well as to the MODIS $550 \mathrm{~nm}$ AOD climatology (not shown). Figure 1a shows a fast westward decrease of the AOD more clearly seen on Fig. $1 \mathrm{~b}$ which displays the 2007 2011 averaged zonal evolution of the AOD from IASI (topleft), and of the total AOD from MODIS(Terra) (top-right), MISR (bottom-left), and PARASOL (bottom-right), from the African coast to the Caribbean, in June, July, and August, for the latitude band $10^{\circ} \mathrm{N}-30^{\circ} \mathrm{N}\left( \pm 3^{\circ}\right.$ longitude, $1^{\circ}$ moving average). All products show a similar fast westward decrease up to $50^{\circ} \mathrm{W}$ and then remaining approximately constant, with differences of the same order of magnitude between $0.55 \mu \mathrm{m}$ AODs as between IASI and the other three products (apart from the ratio observed between IASI $10 \mu \mathrm{m}$ AOD and the $0.55 \mu \mathrm{m}$ AODs and discussed in the next section).

\subsection{Comparison between IASI $10 \mu \mathrm{m}$ AOD and visible MODIS, MISR, and PARASOL AODs at regional scale}

For each of the four regions illustrated in Fig. 2, East-Atlantic (EA), Mid-Atlantic (MA), West Atlantic (WA) and Arabian 

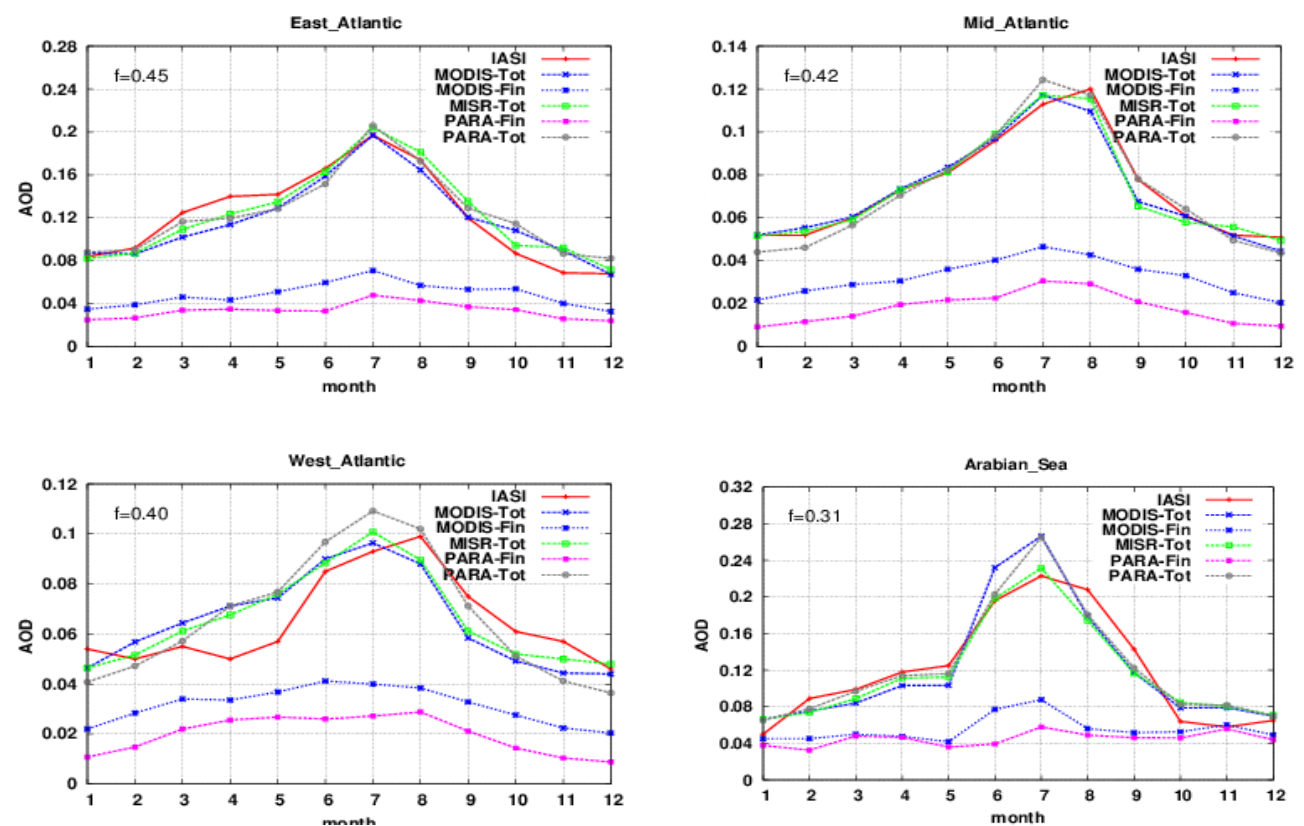

Fig. 3. Climatology of the IASI AOD (10 $\mu \mathrm{m}$, red, this work), and climatologies of the AOD of MODIS-Terra (total: dashed blue; fine mode: dotted blue), MISR (total: green), and PARASOL (total: dashed grey; fine mode: purple) for each region of study. All visible AODs are scaled by the empirically determined IR/VIS ratio shown on each graph (top left label). Average over 4 (January to June) to 5 (July to December) years.

Sea (AS), Figure 3 shows climatologies of the IASI $10 \mu \mathrm{m}$ AOD, the MODIS-Terra, total and fine modes AODs, the MISR total AOD, and the PARASOL total and fine modes AODs, for the period July 2007 to December 2011 (JanuaryJune: 4-yr average; July-December: 5-yr average). It is worth pointing out that, for the sake of an easier comparison, all visible AODs are scaled by the factor shown on each graph (top-left label) of this figure. This scaling factor actually corresponds to the infrared $(10 \mu \mathrm{m})$ to visible $(0.55 \mu \mathrm{m}) \mathrm{AOD}$ ratio, determined here empirically, so as to ensure the best match between the IR and the various visible AODs, taking into account both their climatology and their time series. A physical evaluation of this ratio is not straightforward because of its strong dependence on the microphysical properties of the aerosol considered. It can be obtained by a Lorenz-Mie calculation, given as input the refractive index and a size distribution (see Sect. 2.1). For a bimodal lognormal volumic size distribution, that is supposed to be the more appropriate, it requires knowing its modal volumic radii, widths, and volume concentrations for both fine and coarse modes for the situation considered (Mishchenko et al., 2002; Dubovik et al., 2002). A direct comparison between infrared and visible AODs is thus difficult. However, the comparison of both products brings information on dust size distribution, in particular, on the relative abundance of fine versus coarse mode particles. Sensitivity tests have been performed in order to determine which variables are the main contributors to the IR/VIS ratio. Results show that the ratio of the concentration of fine to coarse mode, followed by the effective radius of the coarse mode have the largest influence. Given the range of values obtained from AERONET retrievals (http://aeronet.gsfc.nasa.gov) during the IASI period on several sites, we found an expected IR/VIS ratio lying between 0.3 and 0.6 , with higher values corresponding to smaller fine mode concentrations. These values are consistent with the ratios empirically found here. In general, IASI compares well with these scaled total visible AOD climatologies but significant differences are also observed.

For region EA, close to the dust sources, IASI AOD well matches the shape of the MODIS, MISR, and PARASOL AODs. The IR/VIS ratio is 0.45 .

For region MA, farther from the sources, the agreement is still good with even smaller differences than for the EA region. The IR/VIS ratio is 0.42 .

Region WA shows an IASI AOD season lagging behind the MODIS (or MISR and PARASOL) dust season. This behaviour had already been pointed out for AIRS in Pey 2010 who explained it by a late arrival of the dust coarse mode compared to the fine mode. This late arrival was confirmed by both AERONET $0.55 \mu \mathrm{m}$ AOD and Angström exponent at La Parguera $\left(18^{\circ} \mathrm{N}, 67^{\circ} \mathrm{W}\right)$ station, showing a fast transition between the two aerosol modes in May/June (see Pey2010 for more details). Note that for regions MA and WA, the MODIS fine mode AOD appears significantly larger than that from PARASOL. The IR/VIS ratio is 0.40 . 

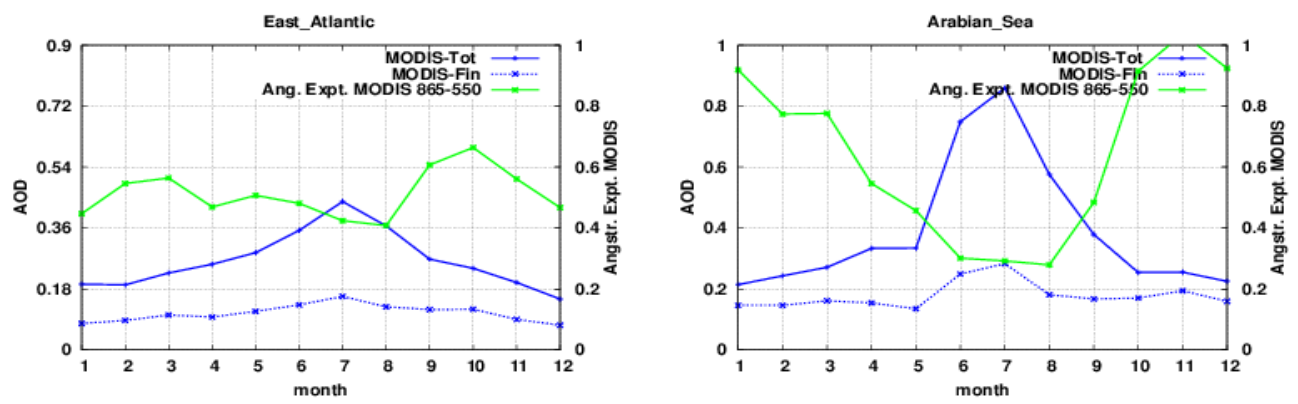

Fig. 4. Climatologies of the MODIS AOD, total (solid blue) and fine mode (dotted blue), left ordinate, and of the MODIS Angström exponent $(865-550 \mathrm{~nm})$ (green, right ordinate), for the two regions EA and AS.

For region AS, covering the Arabian Sea, south of the Arabian Peninsula, the situation is more complex. Significant differences are observed between the various products in June-July and, in August-September, IASI displays slightly larger AODs. Differences are also seen for the four months October-January, with significantly lower IASI AODs. The IR/VIS ratio is 0.31 . These differences can partly be explained by the different behaviour of the MODIS Angström exponent $(865-550 \mathrm{~nm})$ shown on Fig. 4 together with the climatologies of the MODIS total and fine modes AODs for the two regions EA and AS, closest to source regions. While EA region shows a relatively flat Angström exponent, with maxima in September-November and minima in JulyAugust, the AS region shows a pronounced low $(\sim 0.3$ instead of $\sim 0.4$ ) of the Angström exponent in June-August and high values $(>0.9)$ in October-January. This indicates a summer peak period largely dominated by the coarse mode (Smirnov et al., 2002; Eck et al., 2008), seemingly more in phase with the flat PARASOL fine mode AOD than with the MODIS fine mode peak of June-July (Figs. 3 and 4). Moreover, the high Angström exponent values of the four months October-January coincide with the low IASI AOD values for this region (Fig. 3) indicating the dominating influence of the fine mode almost not seen by IASI. For the seven first months, IASI appears more in phase with MISR. For IASI and for this region, however, there may be some doubts about the use of the MITR aerosol model, in particular, because of the presence observed of carbonate minerals from deposits along the Oman/Yemen and United Arab Emirates coasts (Reid et al., 2005, 2008) or the possible mixing of dust with anthropogenic pollution aerosols either from the petroleum industry in the Arabian peninsula or from India.

The IR/VIS ratios shown on Fig. 3 for regions EA $(\sim 0.45)$, MA $(\sim 0.42)$, and WA $(\sim 0.40)$ are consistent with the expected range of ratios obtained from AERONET results, and are in reasonable agreement with values from Highwood et al. (2003) (see also Pierangelo et al., 2004). For region AS, the ratio comes to $\sim 0.31$, much smaller than for the other regions. These ratios reflect, at least in part, the varying distribution of the dust layer between the coarse and the fine modes (and, obviously, the difference between the observation wavelengths).

We also compared the $10 \mu \mathrm{m}$ IASI AOD with the NSCM AOD at $865 \mathrm{~nm}$ derived from PARASOL, both being specific of the dust particle coarse mode. These two AOD climatologies are shown in Fig. 5 together with that of the MODIS Angström exponent $(865-550 \mathrm{~nm})$. To approximately match the IASI AOD, the NSCM AOD has been scaled by a ratio, actually the IR/VIS coarse mode ratio, chosen in such a way that the best agreement is obtained around the peak of the dust season. Indeed, more coarse mode is expected to be present at this time of the year. This ratio corresponds to the only coarse mode and can be estimated theoretically using the same refractive index than previously and a monomodal lognormal distribution. This time, the variables that have the strongest impact on this ratio are the effective radius and the standard deviation of the distribution. Such a ratio decreases with the effective radius and increases with the width of the distribution. For typical values from AERONET, the ratio $10 \mu \mathrm{m}$ IASI AOD/ $865 \mathrm{~nm}$ PARASOL NSCM AOD is expected to lie between 0.7 and 0.9. These values are higher than the one found here, which would imply, if IASI actually retrieves the same coarse mode as the one obtained from PARASOL observations, an underestimation of the IASI AOD. On the other hand, the PARASOL NSCM AOD could also be slightly overestimated. An analysis of the monthly ratio $865 \mathrm{~nm}$ PARASOL NSCM AOD/ $865 \mathrm{~nm}$ PARASOL total AOD leads to values sometimes above 0.9 and even 1.0, higher than the values theoretically expected. Indeed, estimating the coarse mode contribution to the total AOD at $865 \mathrm{~nm}$ (following Pierangelo, 2013) for typical values of the size distribution parameters taken from AERONET, leads to values lower than 0.85 . Nevertheless, with a ratio IASI/ $865 \mathrm{~nm}$ PARASOL NSCM of 0.65 for the EA and the MA regions, a relatively good agreement is found between the two products with a slightly faster start of the IASI season. For both regions and both products, the rapid decrease of the AOD in August-September coincides with the rapid increase of the Angström exponent. With a ratio IASI/PARASOL NSCM of 0.55 (resp. 0.40) for the WA (resp. AS) region, 

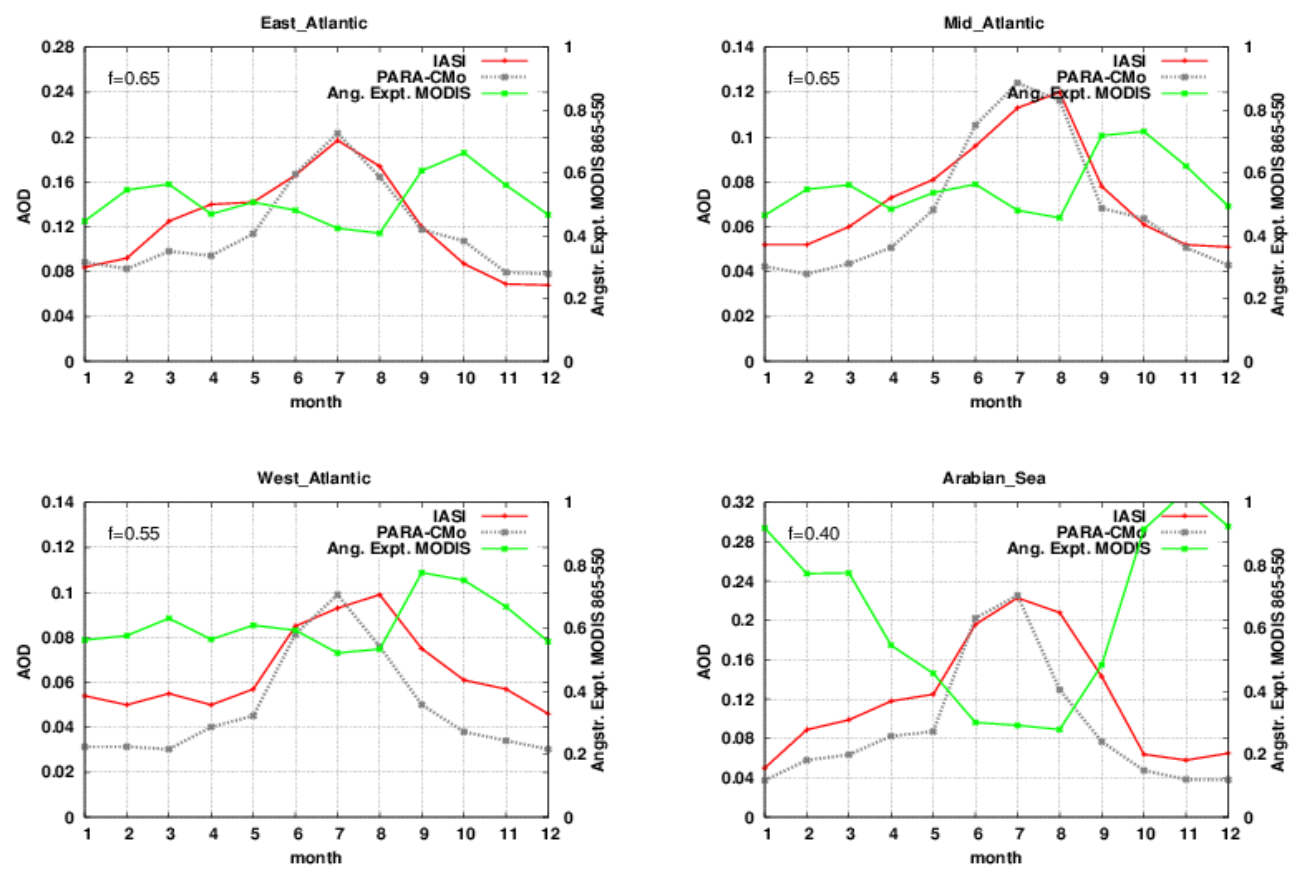

Fig. 5. IASI $10 \mu \mathrm{m}$ AOD climatology (red, left ordinate) and PARASOL non-spherical coarse mode (CMo) AOD at $865 \mathrm{~nm}$ climatology (scaled by the empirically determined IR/VIS ratio shown on each graph: top-left label) for the four regions of study (grey, left ordinate); climatology of the MODIS Angström exponent $(865-550 \mathrm{~nm}$ ) (green, right ordinate). Average over 4 (January to June) to 5 (July to December) years.

the agreement between the two products is significantly less good, particularly outside the peak of the season. For the WA region, however, both products confirm the late start of the dust coarse mode season and show the same sharp Spring transition in May/June. A similar behaviour is observed for the AS region. In both cases, the sharp decrease of IASI AOD in August-September occurs in phase with the increase of the Angström exponent, but occurs one month sooner for the PARASOL NSCM AOD. This makes the IASI season one month longer than seen by PARASOL, again more in phase with the Angström exponent behaviour. In general, the ratio IASI/PARASOL NSCM is smaller to what is expected ( $\sim 0.5$, with the exception of Tenerife). The impact of the dust fine mode on the IASI AOD cannot explain this difference: for dust with a typical bimodal distribution, the fine mode contribution to the total optical depth at $10 \mu \mathrm{m}$ is usually of the order of $10 \%$ (Pierangelo, 2013). Another explanation could come from the (hypothetical) presence of polluted dust (possibly including the hygroscopic growth of the fine mode particles, Smirnov et al., 2002) that present more spherical particles not fully accounted for in the NSCM AOD. This result could also indicate that the use of the MITR model is not appropriate for all the regions, and particularly for AS due to the heterogeneity of the aerosol types observed in this region (Kaskaoutis et al., 2010).

Finally, the interannual variability seen by the visible instruments is also well reproduced by IASI, as shown by their AOD time series for the four regions of study (Fig. 6). Again, region WA well depicts the late arrival of the coarse mode relatively to the fine mode. Some discrepancies are also found, for example, in March-May 2009 for region EA, or in August-September 2010 for region MA.

\subsection{Comparisons between IASI $10 \mu \mathrm{m}$ AOD and visible MODIS, MISR, PARASOL and AERONET AODS at six AERONET sites}

Comparisons between IASI $10 \mu \mathrm{m}$ AOD and visible MODIS, MISR, PARASOL and AERONET AODs have been done at six AERONET sites, namely: Tenerife (La Laguna), Capo Verde, Dakar, Barbados, La Parguera, all in the Atlantic regions, and Karachi, in the AS region (sites indicated by a star on Fig. 2). Figure 7 shows climatologies of the IASI AOD, of the visible AOD from MODIS-Terra (total), MISR (total), PARASOL (total and fine mode), and from AERONET $(500 \mathrm{~nm}$ AOD) at these sites (N.B.: for Capo Verde, the AERONET AOD is at $440 \mathrm{~nm}$ as no $500 \mathrm{~nm}$ AOD is available). Time average is made over 4 (January to June) to 5 (July to December) years for the satellite products. For AERONET data, we consider that at least two years must be reported for averaging. Space average is made over an area $\pm 1.5^{\circ}$ in latitude and longitude, centred on each site; pixels flagged "land" are excluded. On the whole, the agreement between IASI and the other sources of data appears satisfactory with, however, differences from one site to another. 

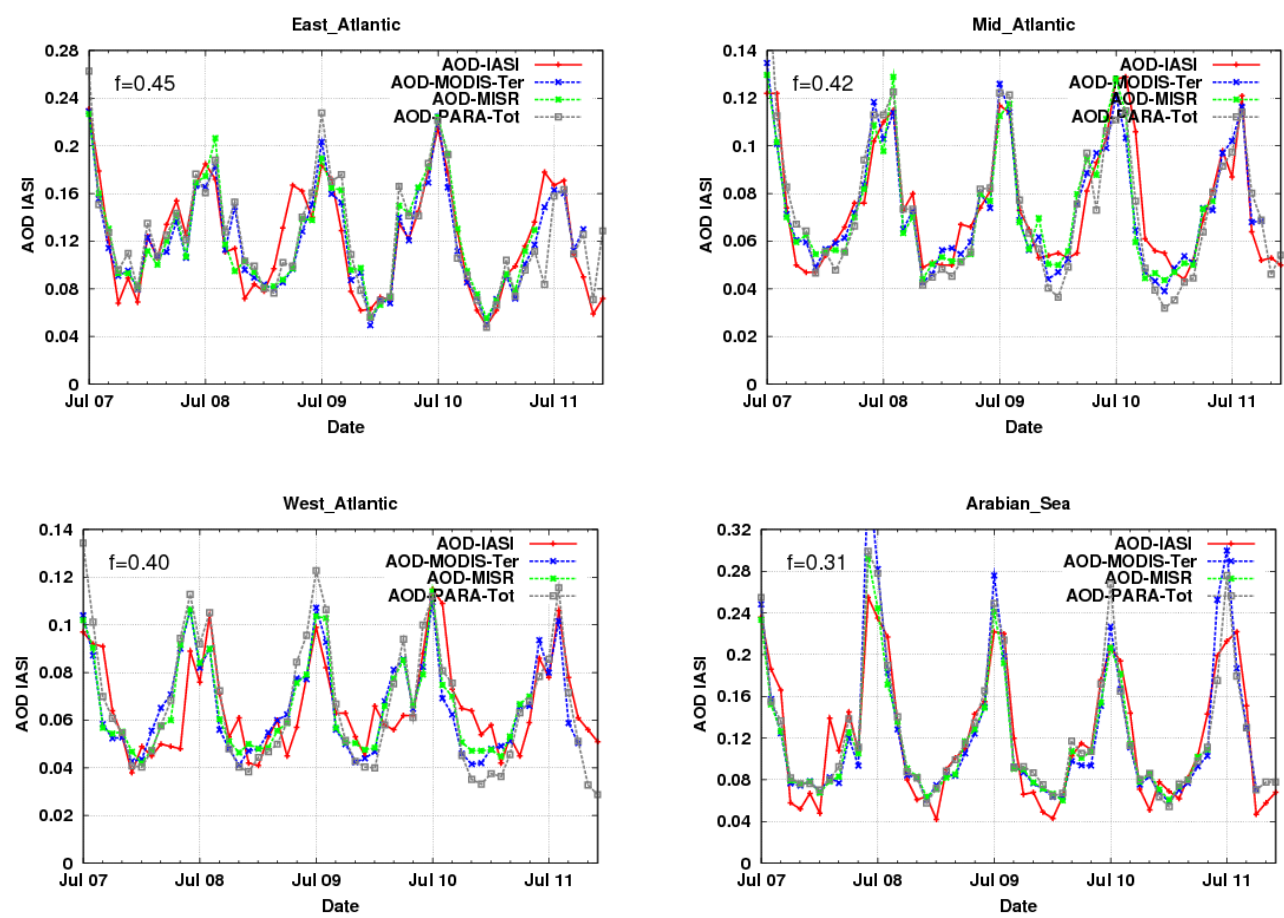

Fig. 6. Time series of the $10 \mu \mathrm{m}$ IASI AOD (red), and of the MODIS-Terra (blue), MISR (green), and PARASOL (grey), total $550 \mathrm{~nm}$ AODs, for the EA region (top left), the MA region (top right), the WA region (bottom left), the AS region (bottom right). All visible AODs are scaled by the empirically determined IR/VIS ratio shown on each graph (top left label).

For Tenerife (La Laguna), IASI and the visible (total) AOD climatologies display similar shapes with relatively small differences. A more pronounced difference is observed between AERONET and the other satellite data, as already reported by Kalashnikova and Kahn (2008) for the neighbouring site of Izana, where this difference is even larger. The meteorological conditions currently prevailing at these sites, marked by strong low level intrusions of cold air, may at least partially explain this problem. At Capo Verde, the IASI dust season starts more rapidly. At Dakar, IASI is more in phase with MISR and AERONET (several months are missing) than with MODIS or PARASOL which peak months appear two to three months later. The reason for this difference is still unclear. At the site of Barbados, far from the sources, IASI AOD is larger than the other AODs in August and decreases less rapidly; at this site, the AERONET AOD is substantially smaller than the other visible AODs, a result also observed by Kalashnikova and Kahn (2008) at the nearby site of Guadeloup $\left(16^{\circ} \mathrm{N}, 61^{\circ} \mathrm{W}\right)$. At La Parguera, the overall agreement is satisfactory but, as for Barbados, the IASI season decreases less rapidly than shown by the other products. For both sites, the PARASOL AOD peak is significantly larger than the other visible AOD peaks. In the Arabian Sea region, at Karachi site, IASI AOD performs relatively well (again larger in August) in spite of our use of the MITR model most probably less adapted to this region.
Figure 8 shows the climatologies of the $10 \mu \mathrm{m}$ IASI AOD, of the PARASOL NSCM AOD at $865 \mathrm{~nm}$, scaled by the IR/VIS ratio (label top-left on each graph) empirically estimated, as in Fig. 5, to approximately match the IASI AOD around the peak of the dust season, and of the MODIS Angström exponent. For Tenerife, the agreement is relatively good with a ratio of 0.95 . At Capo Verde, if the agreement is satisfactory from June to December, IASI starts much more rapidly than the $865 \mathrm{~nm}$ PARASOL NSCM AOD does. It may however be observed that the Spring sharp gradient of the Angström exponent, indicative of a change in the aerosol modes distribution, is more in phase with IASI than with PARASOL. Almost the same situation is observed at Dakar. The IASI AOD, well in phase with the AERONET or MISR AODs (see Fig. 7), peaks two months earlier than the PARASOL NSCM AOD. The situation is different far from the sources (at Barbados and La Parguera) and in the Arabian sea (at Karachi) with IASI dust seasons significantly longer than the PARASOL NSCM ones, but again appearing more in phase with the MODIS Angström exponent gradients, particularly at Barbados. As for the WA and AS regions (Fig. 5), IASI AOD lies significantly above PARASOL outside the summer months.

All together, these comparisons, with differences between IASI and the other products of the same order of magnitude as between the other products themselves, demonstrate the ability of IASI to work properly at small scale. They also 

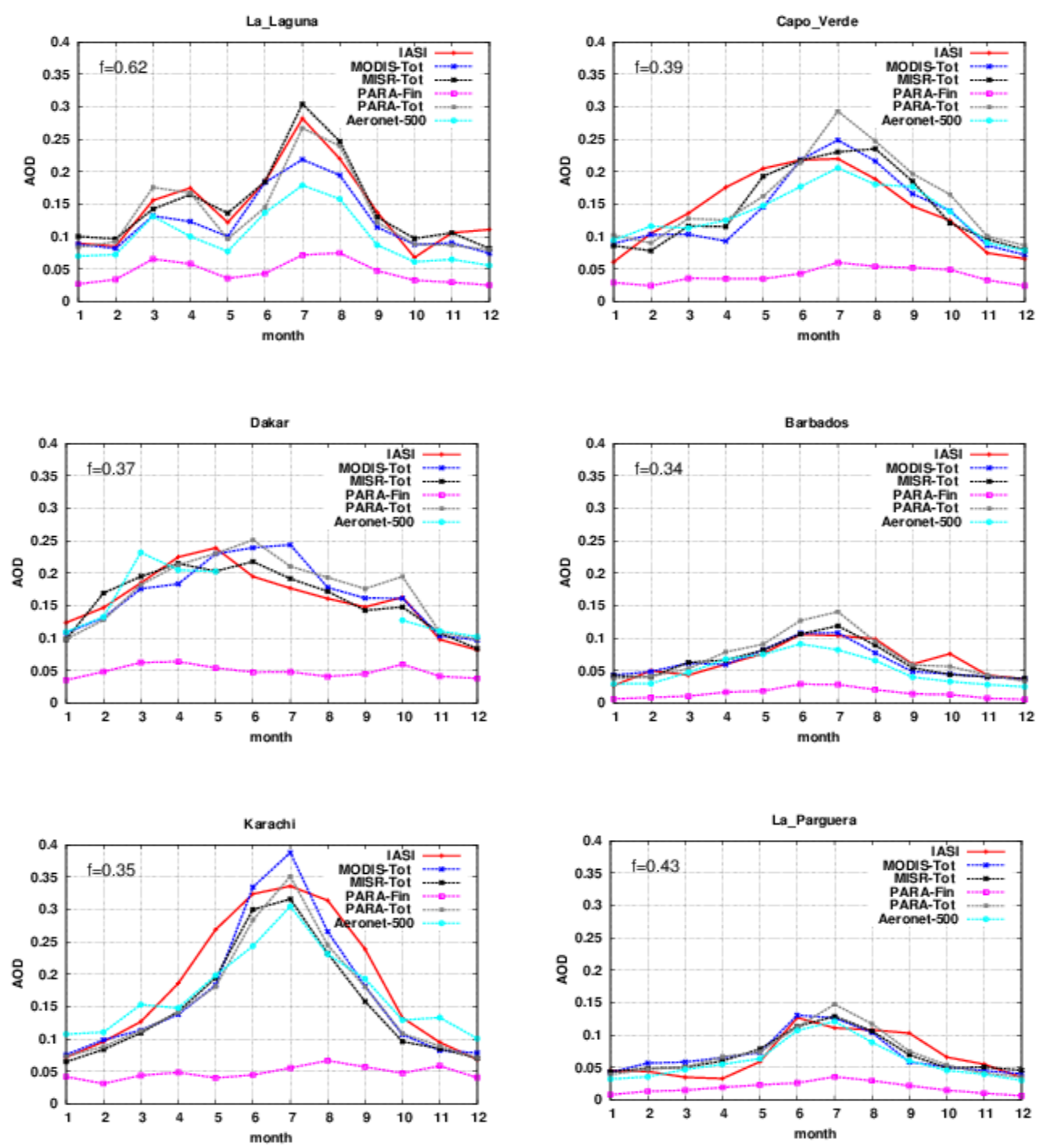

Fig. 7. Climatology of the $10 \mu \mathrm{m}$ IASI AOD (red, left ordinate), and of the AODs from MODIS-Terra (total: blue), MISR (total: green), PARASOL (total: grey; fine mode: purple), and AERONET (500 nm: cyan), right ordinate, for the six AERONET sites. Time average over 4 (January to June) to 5 (July to December) years; space average over an area $\pm 1.5^{\circ}$ in latitude and longitude, centred on each site. N.B.: for Capo Verde, the AERONET AOD is at $440 \mathrm{~nm}$ (no AOD-500 available). Visible AODs are scaled by the empirically determined IR/VIS ratio shown on each graph.

indicate that dust models more adapted to the region (or site) observed have to be constructed and substituted to the MITR model.

\subsection{IASI altitude time series versus CALIOP altitude}

It is worth recalling that the altitudes seen by either IASI or by CALIOP do not correspond to the same definition. For IASI, it is an "infrared-equivalent" altitude, i.e. the altitude at which half of the dust optical depth at $10 \mu \mathrm{m}$ is below and half of the optical depth at $10 \mu \mathrm{m}$ is above, when, for CALIOP, it is the centre of the attenuated backscatter coefficient profile ("centroid").
Figure 9a shows the dust layer monthly mean altitude time series (July 2007-September 2011) for IASI and CALIOP, averaged over regions EA, MA and AS of Fig. 2. For IASI, months with no data correspond to an insufficient number of items in the statistics mostly due to cloudiness or to rejections from the algorithm. Region WA is not shown for the same reason. For these three regions, a clear seasonal cycle is seen, with the monthly mean altitude being higher during summer than during winter. This transport pattern is consistent with conclusions from numerous other studies (see, for example, Prospero et al., 1981; Chiapello et al., 1995, 2005). Averaged over the whole period shown on Fig. 9a, the mean and the standard deviations of the difference between 

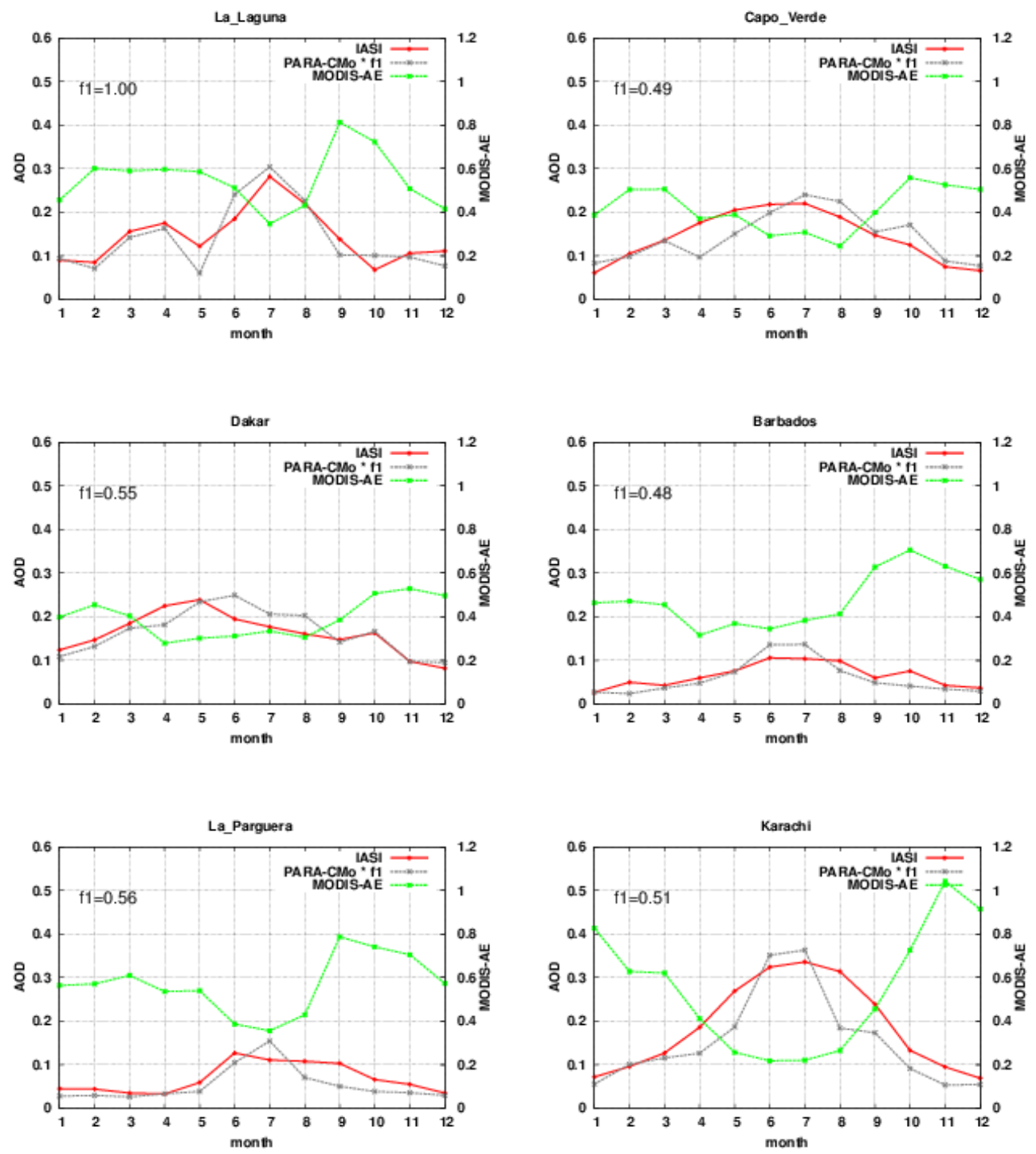

Fig. 8. IASI $10 \mu \mathrm{m}$ AOD climatology (red, left ordinate) versus PARASOL non-spherical coarse mode AOD at $865 \mathrm{~nm}$ climatology (scaled by the empirically determined IR/VIS ratio shown on each graph: top-left label) for the six AERONET sites (grey, left ordinate); climatology of the MODIS Angström exponent $(865-550 \mathrm{~nm}$ ) (green, right ordinate). Average over 4 (January to June) to 5 (July to December) years.

IASI and CALIOP mean altitudes, for regions EA, MA, and AS, respectively, come to $-140 \pm 290 \mathrm{~m},-180 \pm 270 \mathrm{~m}$, and $-220 \pm 470 \mathrm{~m}$. These results illustrate the good consistency between the two products keeping in mind (i), the large difference between the spatial and temporal samplings of the IR sounder and of CALIOP, (ii), the variability associated with IASI and CALIOP altitudes during the summer peak season (of the order of $800 \mathrm{~m}$ and $1 \mathrm{~km}$, respectively), these values more reflecting the variability of the aerosol layer (one month, $1^{\circ}$ ) than the accuracy of the products themselves, (iii), the different definitions of the mean altitude retrieved by IASI or by CALIOP. The agreement is significantly less good for region AS than for the other two, particularly concerning the amplitude of the seasonal cycle. Again, the use of the MITR model may be in question and future plans include the construction of models better adapted to this situation. A relatively slow regular decrease of the altitude from east to west (from about $3 \mathrm{~km}$ at $20^{\circ} \mathrm{W}$ to $1.5 \mathrm{~km}$ at $80^{\circ} \mathrm{W}$ ), already reported in several studies (see, for example, Colarco et al., 2003a, b, and references therein), appears on Fig. 9b, for both CALIOP and IASI. The decrease is somewhat faster for CALIOP from $20^{\circ} \mathrm{W}$ to $60^{\circ} \mathrm{W}$.

This comparison illustrates the ability of infrared sounders to retrieve dust aerosols altitude that compare relatively well with that of CALIOP. 

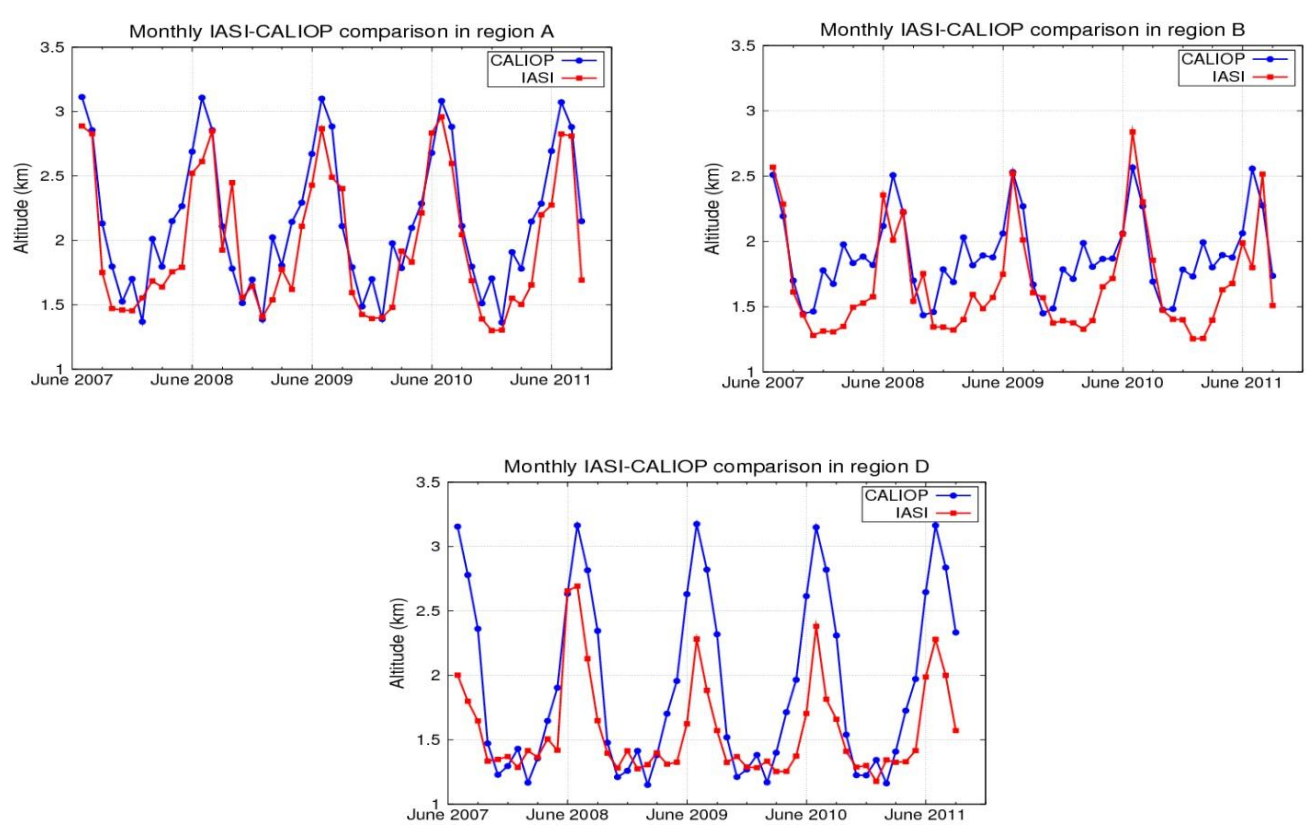

Fig. 9a. Altitude (km) time series of IASI (red), and CALIOP (blue), for the period July 2007 to September 2011, and for the regions EA (top left), MA (top right), and AS (bottom).
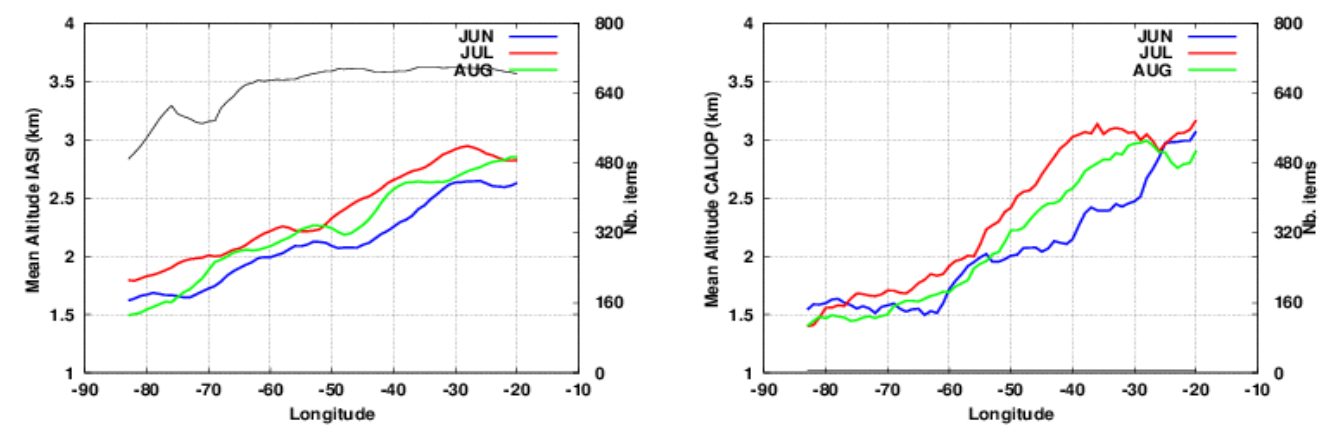

Fig. 9b. 2007-2011 averaged zonal evolution of the IASI (left) and CALIOP (right) altitude, from the African coast to the Caribbean, in June (blue), July (red), and August (green). Data are averaged over the latitude band $10^{\circ} \mathrm{N}-30^{\circ} \mathrm{N}$ and over $\pm 3^{\circ}$ longitude, around the longitude considered. Black solid line: number of items for July (right ordinate).

\subsection{IASI dust coarse mode effective radius}

As reported in Pierangelo et al. (2005), the sensitivity of infrared BTs to the particle size is a few tenths of Kelvin, an order of magnitude smaller than their sensitivity to either AOD or altitude, making it only slightly larger than the IASI radiometric noise. Moreover, the smaller the AOD the smaller the sensitivity to the radius, and the less reliable the retrieved radius. Figure 10a presents the monthly climatology $\left(1^{\circ} \times 1^{\circ}\right)$ of the IASI-retrieved dust coarse mode effective radius $\left(R_{\text {eff }}\right)$ for the period $07 / 2007-12 / 2011$. As expected, months outside the dust season appear noisier. Cleaner results are obtained within the period April-May to September. This 5-yr monthly climatology reveals relatively small variations of $R_{\text {eff }}$, from highest values of about 2.2$2.3 \mu \mathrm{m}$ close to the African coasts and over the Arabian Sea to lowest values around $1.8-1.9 \mu \mathrm{m}$, mostly at the southern or northern edges of the dust layer. Figure $10 \mathrm{~b}$ shows the 2007-2011 averaged zonal evolution of the IASI effective radius, from the African coast to the Caribbean, in June, July, and August. Data are averaged over the latitude band $10^{\circ} \mathrm{N}-30^{\circ} \mathrm{N}$ and over $\pm 3^{\circ}$ longitude, around the longitude considered. With an almost constant value of about $2 \mu \mathrm{m}$, this figure confirms the findings of Maring et al. (2003a) who had noted that "Normalized mineral dust size distributions of particles smaller than $7.3 \mu \mathrm{m}$ over the Canary Islands and Puerto Rico were indistinguishable, indicating these particles were not preferentially removed during atmospheric transport" (see also Christopher and Jones, 2010). IASI-retrieved radius values are in reasonable agreement with AERONET-retrieved dust coarse mode effective radius 


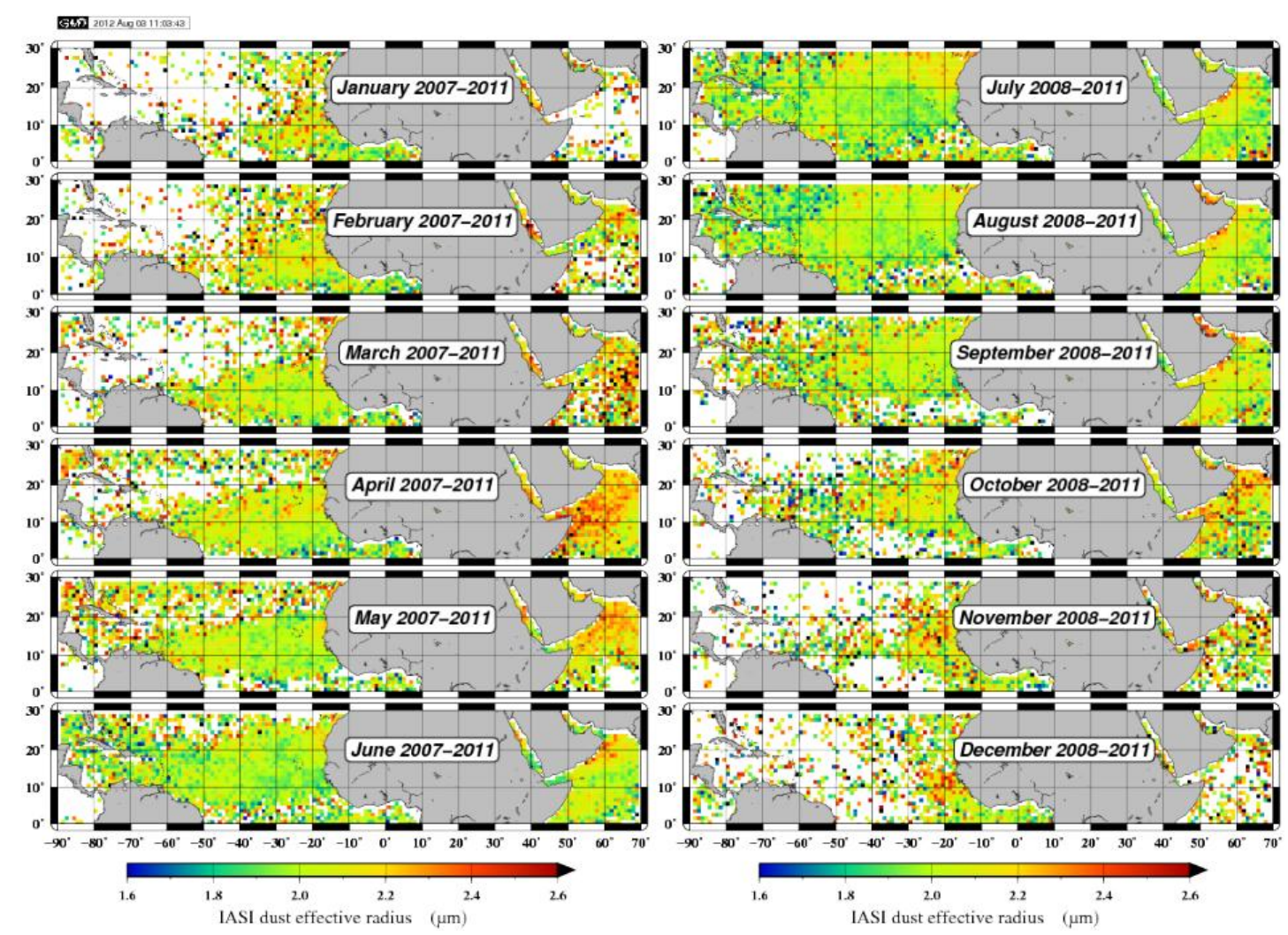

Fig. 10a. IASI-retrieved dust coarse mode effective radius $(\mu \mathrm{m})$ climatology. Average over 4 (January to June) to 5 (July to December) years.

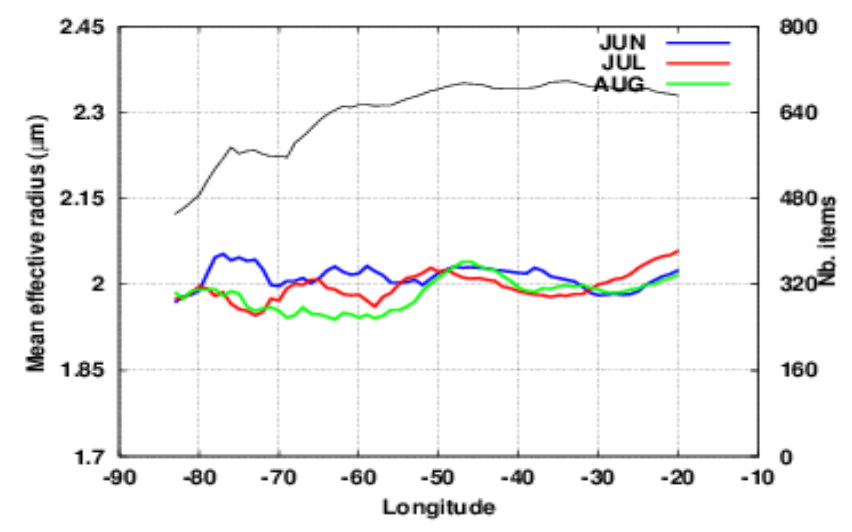

Fig. 10b. Same as Fig. $9 \mathrm{~b}$ for the IASI radius.

monthly mean values (http://aeronet.gsfc.nasa.gov/new_web/ optical_properties.html) at various sites. Preliminary comparisons have brought into evidence an overall systematic positive bias of $\sim+0.35 \mu \mathrm{m}$ between IASI and AERONET retrievals. To facilitate the comparison, this bias, still not understood, has then been removed from the IASI results of Fig. 11, a choice which does not mean that more confidence should be given to either AERONET or to IASI. This figure shows the dust coarse mode effective radius climatology from IASI and from AERONET at the six sites consid- ered here. IASI retrieved AOD (grey) is also shown (right ordinate). IASI missing months correspond to too small IASI AODs $(<0.04)$. Here again, small variations of $R_{\mathrm{eff}}$ are seen, with noisier IASI results at La Laguna (Tenerife) and Karachi. As for the AOD, the site of La Laguna shows different results with a larger positive bias of $\sim 0.50 \mu \mathrm{m}$ $(0.35+0.15)$. A rather good agreement comes out from these comparisons (however, still too limited) with this quasi operational network. Such comparisons also raise the question of the accuracy of AERONET measurements (Ryder et al., 2013; Müller et al., 2012). Comparisons with in situ campaign measurements are more problematic as shown by Reid et al. (2003a) who compared various methods of measurement of dust particles coarse mode from Africa and emphasised the uncertainties in the sizing methods and on the ambiguities in the size parameters. It is worth noting that Müller et al. (2012), comparing AERONET data and airborne measurements during the SAMUM 2006 campaign, found out that the effective radius of the coarse mode fraction of mineral dust derived from sun photometer was twice as small as that from the airborne observations. 

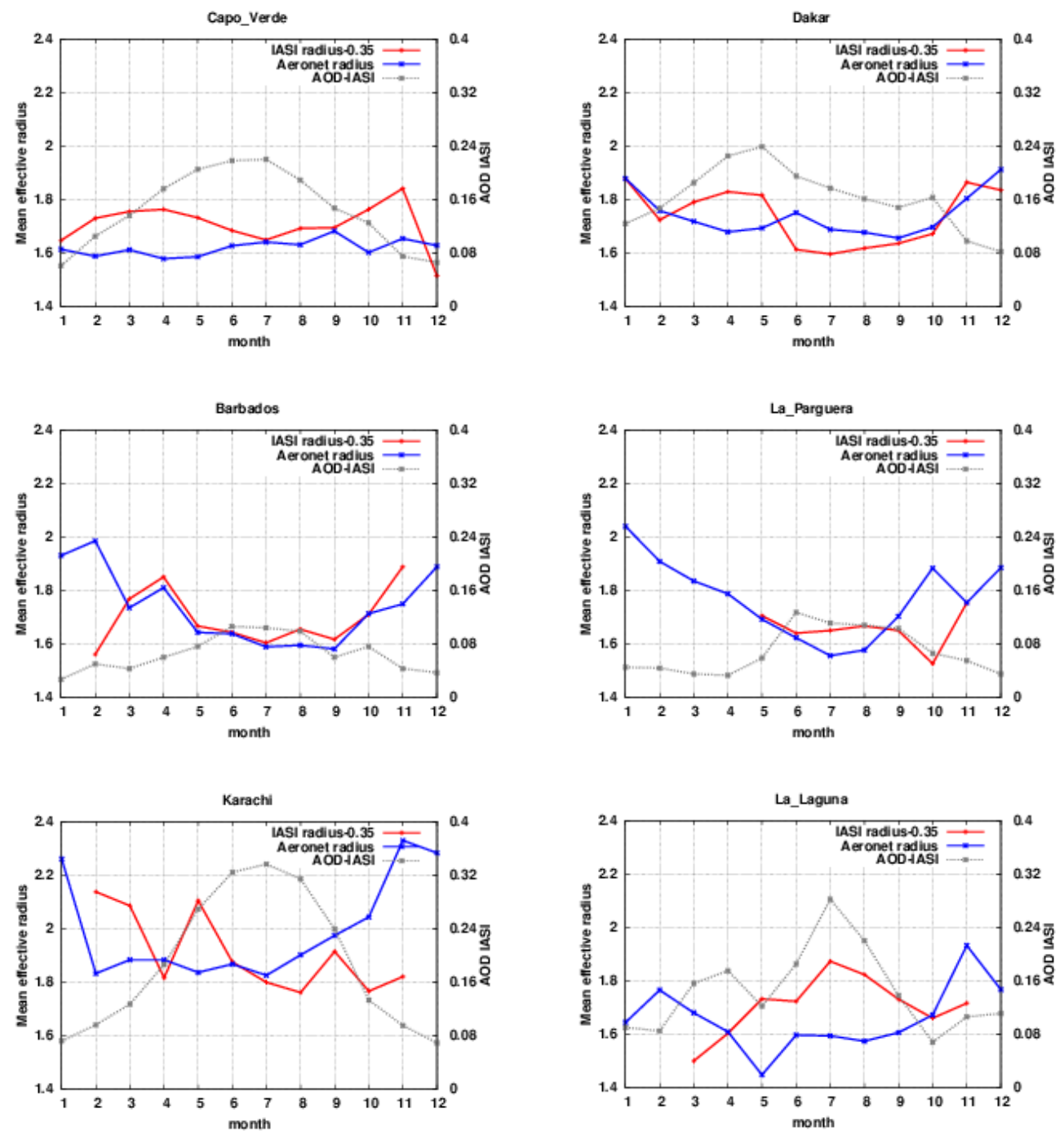

Fig. 11. Dust coarse mode effective radius climatology from IASI (red) and AERONET (blue) for the six AERONET sites. IASI retrieved AODs (dotted grey) are also shown (right ordinate). IASI missing months are due to too small AODs $(<0.04)$ or to not enough items in the statistics. A systematic bias of $0.35 \mu \mathrm{m}$ has been subtracted to IASI radius results (see text).

\section{Discussion and conclusions}

The main characteristics of the northern tropical Atlantic and Arabian Sea dust aerosol layers, i.e. $10 \mu \mathrm{m}$ AOD, mean altitude, and coarse mode effective radius, have been retrieved from IASI and compared with MODIS-Terra (no significant differences seen with Aqua at the monthly level) total and fine modes AOD, MISR total AOD, PARASOL total, fine and non-spherical coarse modes AOD, AERONET AOD, CALIOP mean altitude, and AERONET radius retrievals. Such comparisons have been made at regional scale, over the northern tropical Atlantic and the Arabian Sea, as well as at local scale around six AERONET sites. The retrieval method is a three-step algorithm (retrieval of (i), the atmospheric environment, (ii), of the AOD and altitude, (iii), of the effective radius), based on the use of Look-Up-Tables computed using the 4A/OP-DISORT radiative transfer model in its operational version. Use is made of the MITR aerosol model from the OPAC database (Hess et al., 1998).

Maps of the aerosol $10 \mu \mathrm{m}$ IASI AOD over the Atlantic Ocean illustrate the main patterns of dust transport: during the May-September dust season, a fast westward decrease of the optical depth is observed, from about 0.2 at the African coast to about 0.1 at $\sim 55^{\circ} \mathrm{W}$. This value remains approximately constant up to the Caribbean. MODIS, MISR and PARASOL visible AODs at $550 \mathrm{~nm}$ confirm these results.

Comparisons at regional scale (three regions of the northern tropical Atlantic: East Atlantic (EA), Mid-Atlantic (MA), West Atlantic (WA) and one region of the Arabian Sea (AS)) show a good agreement between IASI and the other instruments either during the summer peak of the dust season or outside of it. Differences between IASI AODs and the 
properly scaled (see Sect. 3.2) $0.55 \mu \mathrm{m}$ AODs are of the same order of magnitude as between them. The IR AOD to Visible AOD ratio is found to vary with the region, from about 0.45 eastward to 0.40 westward and 0.31 for the Arabian Sea, reflecting, at least in part, the varying distribution of the dust layer between the coarse and the fine modes (and, obviously, the difference between the observation wavelengths). These ratios are in reasonable agreement with values expected from AERONET and with already published values (Highwood et al., 2003). Both expected to be representative of the dust coarse mode, the climatologies of the $10 \mu \mathrm{m}$ IASI AOD and of the PARASOL non-spherical coarse mode (NSCM) AOD at $865 \mathrm{~nm}$, compare well for the two regions EA and MA even if the ratio AOD IASI/ PARASOL NSCM AOD is lower than theoretically expected. For the two regions WA and AS, the comparison reveals a coarse mode dust season longer for IASI than for PARASOL NSCM, the former seemingly more in phase with the MODIS 865-550 nm Angström exponent gradients. Outside the season, the ratio IASI AOD/ PARASOL NSCM AOD is significantly larger than inside. This result could indicate that the use of the MITR model is not appropriate for all the regions, and particularly for AS. Another explanation could come from the presence of large, more spherical, polluted dust particles, including the hygroscopic growth of the fine mode particles (Smirnov et al., 2002; Eck et al., 2008; Basart et al., 2009), not fully accounted for in the NSCM AOD. Still at regional scale, time series of the IASI AOD illustrate the dust natural cycle as well as its interannual variability, in good agreement with $0.55 \mu \mathrm{m}$ AODs.

On a local scale, around six AERONET sites, results are similar with a general good agreement between IASI and the other instruments or the AERONET AODs. Two noticeable exceptions for the latter are Tenerife (La Laguna) and Barbados with all space-borne instruments (including IASI) measuring too high AODs compared to AERONET, particularly in summer. This discrepancy had already been observed by Kalashnikova and Kahn (2008). Conclusions similar to that obtained at regional scale are obtained when comparing IASI AOD to PARASOL NSCM AOD with largest differences observed outside the dust season for sites far from the sources (Barbados and La Parguera).

A relatively slow regular decrease of the altitude from east to west (from about $3 \mathrm{~km}$ at $20 \mathrm{~W}$ to $1.5 \mathrm{~km}$ at $80^{\circ} \mathrm{W}$ ), already reported in several studies (see, for example, Colarco et al., 2003a, b; Ben-Ami et al., 2009; Tsamalis et al., 2013), appears on Fig. 9b, for both CALIOP and IASI. The decrease is somewhat faster for CALIOP $\left(\sim 25 \mathrm{~m} \mathrm{deg}^{-1}\right)$ than for IASI $\left(\sim 20 \mathrm{~m} \mathrm{deg}^{-1}\right)$. The agreement between IASI and CALIOP mean altitudes is quite satisfactory (bias of the order of $-0.25 \mathrm{~km}$ and standard deviation of the order of $0.28 \mathrm{~km}$, averaged over the whole period studied) for the regions EA and MA, slightly less satisfactory for the AS region $(-0.22 \mathrm{~km}$ and $0.47 \mathrm{~km}$, respectively). Not enough items are available for region WA. These results must be analysed having in mind the large difference between the spatial and temporal samplings of these two sounders, and the different definitions of the mean altitude retrieved by IASI and by CALIOP. Such results illustrate the capability of IR sounders to retrieve a meaningful dust layer altitude on a global scale over ocean.

Another interesting feature of this work is the retrieval of the dust coarse mode effective radius $\left(R_{\text {eff }}\right)$ from IASI, a variable of prime importance for the study of dust radiative forcing, transport and deposition. The method developed follows that of Pierangelo et al. (2005). A 5-yr climatology of the dust effective radius has been obtained, revealing relatively small variations of $R_{\text {eff }}$, from highest values of about 2.22.3 close to the African coasts and over the Arabian Sea to lowest values around $1.8-1.9 \mu \mathrm{m}$, mostly at the southern or northern edges of the dust layer. This result agrees with the findings of the PRIDE campaign (Maring et al., 2003a, b; Reid et al., 2003b). Compared to AERONET-retrieved values, these results bring into evidence a positive bias of IASI of about $0.35 \mu \mathrm{m}$. Work is in progress to explain this difference. The main interest of the present results is to bring a global and consistent view of the coarse mode dust particle size throughout its transport to the Caribbean and over the Arabian Sea.

Further potential improvements are numerous: increase of the IASI aerosol products space-time resolution from $\left(1^{\circ}, 1\right.$ month) to (1 spot, 1 day) (Tsamalis et al., 2011); retrieval of dust characteristics over land, using maps of the infrared surface emissivity at high spectral resolution $(0.05 \mu \mathrm{m})$ and skin temperature retrieved from IASI (Capelle et al., 2012); extension in latitude; improvements of the assumptions concerning the aerosol models presently used. Future work also includes deeper validation/evaluation of the present aerosol products. Finally, CNES has begun feasibility studies on a new-generation atmospheric sounding interferometer (IASINext Generation) to be flown aboard the second-generation MetOp satellites. IASI NG will improve the IASI performances by a factor of two in both the spectral resolution and radiometric noise, leading to major improvements in the accuracy of retrieved aerosol characteristics: AOD, altitude, and, particularly, effective radius.

Acknowledgements. MODIS and MISR data were obtained through NASA Giovanni, an online visualisation and analysis tool maintained by the Goddard Earth Sciences (GES) Data and Information Services Centre (DISC). PARASOL data have been extracted from the archive maintained by the ICARE datacenter (http://www.icare.univ-lille1.fr/). We thank the PI investigators and their staff for establishing and maintaining the AERONET sites used in this investigation. We are also happy to thank the ICARE Thematic Centre for providing us with CALIPSO/CALIOP data (http://www.icare.univ-lille1.fr/). This work has been supported in part by the European Community under the Grant Agreement no. 283576 (MACC project) and by CNRS, CNES and Ecole Polytechnique. We have also benefited from the large facilities of IDRIS, the computer centre of CNRS. 
Edited by: E. Highwood

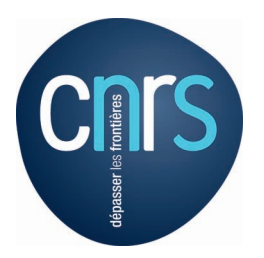

The publication of this article is financed by CNRS-INSU.

\section{References}

Basart, S., Pérez, C., Cuevas, E., Baldasano, J. M., and Gobbi, G. P.: Aerosol characterization in Northern Africa, Northeastern Atlantic, Mediterranean Basin and Middle East from direct-sun AERONET observations, Atmos. Chem. Phys., 9, 8265-8282, doi:10.5194/acp-9-8265, 2009.

Ben-Ami, Y., Koren, I., and Altaratz, O.: Patterns of North African dust transport over the Atlantic: winter vs. summer, based on CALIPSO first year data, Atmos. Chem. Phys., 9, 7867-7875, doi:10.5194/acp-9-7867-2009, 2009.

Ben-Ami, Y., Koren, I., Altaratz, O., Kostinski, A., and Lehahn, Y.: Discernible rhythm in the spatio/temporal distributions of transatlantic dust, Atmos. Chem. Phys., 12, 2253-2262, doi:10.5194/acp-12-2253-2012, 2012.

Capelle, V., Chédin, A., Péquignot, E., Schlüssel, P., Newman, S. M., and Scott, N. A.: Infrared continental surface emissivity spectra and skin temperature retrieved from IASI observations over the tropics. J. Appl. Meteor. Climatol., 51, 1164-1179, doi:10.1175/JAMC-D-11-0145.1, 2012.

Chalon, G., Cayla, F., and Diebel, D.: IASI: An Advanced Sounder for Operational Meteorology, Proceedings of the 52nd Congress of IAF, Toulouse France, October 2001, 2001.

Chiapello, I., Bergametti, G., Gomes, L., Chatenet, B., Dulac, F., Pimenta, J., and Santos Suares, E.: An additional low layer transport of Sahelian and Saharan dust over the North-Eastern Tropical Atlantic, Geophys. Res. Lett., 22, 3191-3194, 1995.

Chiapello, I., Moulin, C., and Prospero, J. M.: Understanding the long-term variability of African dust transport across the Atlantic as recorded in both Barbados surface concentrations and large-scale Total Ozone Mapping Spectrometer (TOMS) optical thickness, J. Geophys. Res., 110, D18S10, doi:10.1029/2004JD005132, 2005.

Christopher, S. A. and Jones, T.: Satellite and surface-based remote sensing of Saharan dust aerosols, Remote Sens. Environ., 114, 1002-1007, doi:10.1016/j.rse.2009.12.007, 2010.

Colarco, P. R., Toon, O. B., and Holben, B. N.: Saharan dust transport to the Caribbean during PRIDE: 1. Influence of dust sources and removal mechanisms on the timing and magnitude of downwind aerosol optical depth events from simulations of in situ and remote sensing observations, J. Geophys. Res., 108, 8589, doi:10.1029/2002JD002658, 2003a.

Colarco P. R., Toon, O. B., Reid, J. S., Livingston, J. M., Russell, P. B. Redemann, J. Schmid, B., Maring, H. B., Savoie, D., Welton, E. J., Campbell, J. R., Holben, B. N., and Levy, R.: Saharan dust transport to the Caribbean during PRIDE: 2. Transport, vertical profiles, and deposition in simulations of in situ and remote sensing observations, J. Geophys. Res., 108, 8590, doi:10.1029/2002JD002659, 2003b.
De Souza-Machado, S., Strow, L. L., Motteler, H., and Hannon, S.: Infrared dust spectral signatures from AIRS, Geophys. Res. Lett., 33, L03801, doi:10.1029/2005GL024364, 2006.

Deschamps, P.-Y., Bréon, F.-M., Leroy, M., Podaire, A., Bricaud, A., Buriez, J.-C., and Sèze, G.: The POLDER mission: Instrument characteristics and scientific objectives. IEEE Trans. Geosci. Remote Sens., 32, 598-615, 1994.

Diner, D. J., Beckert, J. C., Bothwell, G. W., and Rodriguez J. I.: Performance of the MISR Instrument During Its First 20 Months in Earth Orbit, IEEE. Trans. Geosci. Rempte Sens. 40, 14491466, 2002.

Dubovik, O., Holben, B., Eck, T., Smirnov, A., Kaufmann, Y., King, M., Tanré, D., and Slutsker, I.: Variability of absorption and optical properties of key aerosol types observed in worldwide locations, J. Atmos. Sci., 59, 590-608, 2002.

Eck, T. F., Holben, B. N., Reid, J. S., Sinyuk, A., Dubovik, O., Smimov, A., Giles, D., O’Neill, N. T., Tsay S.-C., Ji, Q., Al Mandoos, A., Ramzan Khan, M., Reid, E. A., Schafer, J. S., Sorokine, M., Newcomb, W., and Slutsker, I.: Spatial and temporal variability of column-integrated aerosol optical properties in the southern Arabian Gulf and United Arab Emirates in summer, J. Geophys. Res., 113, D01204, doi:10.1029/2007JD008944, 2008.

Formenti, P., Schütz, L., Balkanski, Y., Desboeufs, K., Ebert, M., Kandler, K., Petzold, A., Scheuvens, D., Weinbruch, S., and Zhang, D.: Recent progress in understanding physical and chemical properties of African and Asian mineral dust, Atmos. Chem. Phys., 11, 8231-8256, doi:10.5194/acp-11-8231-2011, 2011.

Hess, M., Koepke, P., and Schult, I.: Optical Properties of Aerosols and Clouds: The software package OPAC, B. Am. Meteor. Soc., 79, 831-844, 1998.

Highwood, E., Haywood, J. M., Silverstone, M. D., Newman, S. M., and Taylor, J. P.: Radiative properties and direct effect of Saharan dust measured by the C-130 aircraft during Saharan Dust Experiment (SHADE), 2. Terrestrial spectrum, J. Geophys. Res., 108, 8578, doi:10.1029/2002JD002552, 2003.

Huang, J., Zhang, C., and Prospero, J. M.: African dust outbreaks: A satellite perspective of temporal and spatial variability over the tropical Atlantic Ocean, J. Geophys. Res., 115, D05202, doi:10.1029/2009JD012516, 2010.

IPCC: Climate Change - The Physical Science Basis, Contribution of Working Group I to the Fourth Assessment Report of the IPCC, ISBN 9780521 88009-1 Hardback; 9780521 70596-7 Paperback, 2007.

Kalashnikova, O. V. and Kahn, R. A.: Mineral dust plume evolution over the Atlantic from MISR and MODIS aerosol retrievals, J. Geophys. Res., 113, D24204, doi:10.1029/2008JD010083, 2008.

Karyampudi, V., Palm, S., Reagen, J., Fang, H., Grant, W., Hoff, R., Moulin, C., Pierce, H., Torres, O., Browell, E., and Melfi, S.: Validation of the Saharan dust plume conceptual model using Lidar, Meteosat, and ECMWF Data, B. Am. Meteorol. Soc., 80, 1045-1075, 1999.

Kaskaoutis, D. G., Kalapureddy, M. C. R., Krishna Moorthy, K., Devara, P. C. S., Nastos, P. T., Kosmopoulos, P. G., and Kambezidis, H. D.: Heterogeneity in pre-monsoon aerosol types over the Arabian Sea deduced from ship-borne measurements of spectral AODs, Atmos. Chem. Phys., 10, 4893-4908, doi:10.5194/acp-10-4893-2010, 2010.

Kaufman, Y., Koren, I., Remer, L., Tanré, D., Ginoux, P., and Fan, S.: Dust transport and deposition observed from the terramod- 
erate resolution imaging spectroradiometer (MODIS) spacecraft over the Atlantic Ocean, J. Geophys. Res., 110, D10S12, doi:10.1029/2003JD004436, 2005.

Kim, S.-W., Berthier, S., Raut, J.-C., Chazette, P., Dulac, F., and Yoon, S.-C.: Validation of aerosol and cloud layer structures from the space-borne lidar CALIOP using a ground-based lidar in Seoul, Korea, Atmos. Chem. Phys., 8, 3705-3720, doi:10.5194/acp-8-3705-2008, 2008.

Klüser, L., Martynenko, D., and Holzer-Popp, T.: Thermal infrared remote sensing of mineral dust over land and ocean: a spectral SVD based retrieval approach for IASI, Atmos. Meas. Tech. 4, 757-773. doi:10.5194/amt-4-757, 2011.

Klüser, L., Kleiber, P., Holzer-Popp, T., and Grassian, V. H.: Desert dust observation from space - Application of measured mineral component infrared extinction spectra, Atmos. Environ., 54, 419-427, 2012.

Knippertz, P. and Todd, M. C.: Mineral dust aerosols over the Sahara: Meteorological controls on emission and transport and implications for modeling, Rev. Geophys., 50, RG1007, doi:10.1029/2011RG000362, 2012.

Legrand, M., Bertrand, J. J., Desbois, M., Menenger, L., and Fouquart, Y.: The potential of infrared satellite data for the retrieval of saharan-dust optical depth over Africa, J. Appl. Meteorol., 28, 309-319, doi:10.1175/15200450, 1989.

Maher, B. A., Prospero, J. M., Mackie, D., Gaiero, D., Hesse, P. P., and Balkanski, Y.: Global connections between aeolian dust, climate and ocean biogeochemistry at the present day and at the last glacial maximum, Earth-Sci. Rev., 99, 61-97, doi:10.1016/j.earscirev.2009.12.001, 2010.

Mahowald, N. M., Kloster, S., Engelstaedter, S., Moore, J. K., Mukhopadhyay, S., McConnell, J. R., Albani, S., Doney, S. C., Bhattacharya, A., Curran, M. A. J., Flanner, M. G., Hoffman, F. M., Lawrence, D. M., Lindsay, K., Mayewski, P. A., Neff, J., Rothenberg, D., Thomas, E., Thornton, P. E., and Zender, C. S.: Observed 20th century desert dust variability: impact on climate and biogeochemistry, Atmos. Chem. Phys., 10, 10875-10893, doi:10.5194/acp-10-10875-2010, 2010.

Maring, H., Savoie, D. L., Izaguirre, M., Custals, L., and Reid, J.: Mineral dust aerosol size distribution change during atmospheric transport, J. Geophys. Res., 108, 8592, doi:10.1029/2002JD002536, 2003a.

Maring, H., Savoie, D. L., Izaguirre, M. A., Custals, L., and Reid, J. S.: Vertical distributions of dust and sea-salt aerosols over Puerto Rico during PRIDE measured from a light aircraft, J. Geophys. Res., 108, 8587, doi:10.1029/2002JD002544, 2003 b.

Mishchenko, M. I., Travis, L. D., and Lacis, A. A.: Scattering, Absorption, and Emission of Light by Small Particles, Cambridge University Press, Cambridge, 2002.

Müller, D., Lee, K.-H., Gasteiger, J., Tesche, M., Weinzierl, B., Kandler, K., Müller, T., Toledano, C., Otto, S., Althausen, D., and Ansmann, A.: Comparison of optical and microphysical properties of pure Saharan mineral dust observed with AERONET Sun photometer, Raman lidar, and in situ instruments during SAMUM 2006, J. Geophys. Res., 117, D07211, doi:10.1029/2011JD016825, 2012.

Peyridieu, S.: Etablissement d'une climatologie des propriétés des aérosols de poussières à partir d'observations hyperspectrales dans l'infrarouge. Application aux instruments AIRS et IASI. Ph.D. Thesis, Université Pierre et Marie Curie (UPMC), Paris,
France, December 2010 (in French).

Peyridieu, S., Chédin, A., Tanré, D., Capelle, V., Pierangelo, C., Lamquin, N., and Armante, R.: Saharan dust infrared optical depth and altitude retrieved from AIRS: a focus over North Atlantic - comparison to MODIS and CALIPSO, Atmos. Chem. Phys., 10, 1953-1967, doi:10.5194/acp-10-1953-2010, 2010.

Pierangelo, C., Chédin, A., Heilliette, S., Jacquinet-Husson, N., and Armante, R.: Dust altitude and infrared optical depth from AIRS, Atmos. Chem. Phys., 4, 1813-1822, doi:10.5194/acp-41813-2004, 2004.

Pierangelo, C., Mishchenko, M., Balkanski, Y., and Chédin, A.: Retrieving the effective radius of Saharan dust coarse mode from AIRS, Geophys. Res. Lett., 32, L20813, doi:10.1029/2005GL023425, 2005.

Pierangelo, C.: Longwave passive remote sensing, in: Aerosol Remote Sensing, edited by: Lenoble, J., Remer, L., and Tanré, D., Chapter 9, Springer-Praxis Books in Environmental Sciences, 390 pp., ISBN 978-3-642-17724-8, 2013.

Prospero, J. M., Glaccum, R. A., and Nees, R. T.: Atmospheric transport of soil dust from Africa to South America, Nature, 289, 570-572, 1981.

Reid, J. S., Jonsson, H., Maring, H., Smirnov, A., Savoie, D., Cliff, S., Reid, E., Livingston, J., Meier, M., Dubovik, O., and Tsay, S.: Comparison of size and morphological measurements of coarse mode dust particles from Africa, J. Geophys. Res., 108, 8593, doi:10.1029/2002JD002485, 2003a.

Reid, J. S., Kinney, J., Westphal, D., Holben, B., Welton, E., Tsay, S.-C., Eleuterio, D., Campbell, J., Christopher, S., Colarco, P., Jonsson, H., Livingston, J., Maring, H., Meier, M., Pilewskie, P., Prospero, J., Reid, E., Remer, L., Russell, P., Savoie, D., Smirnov, A., and Tanré, D.: Analysis of measurements of Saharan dust by airborne and groundbased remote sensing methods during the Puerto Rico Dust Experiment (PRIDE), J. Geophys. Res., 108, 8586, doi:10.1029/2002JD002493, 2003b.

Reid, J. S., Piketh, S. J., Kahn, R. R., Bruintjes, R. T., and Holben, B. N.: A Summary of First Year Activities of the United Arab Emirates Unified Aerosol Experiment: UAE2, Naval Research Laboratory report nb. NRL/MR/7534-05-8899, 150 pp., 2005.

Reid, J. S., Piketh, S. J., Walker, A. L., Burger, R. P., Ross, K. E., Westphal, D. L., Bruintjes, R. T., Holben, B. N., Hsu, N. C., Jensen, T. L., Kahn, R. A., Kuciauskas, A. P., Mandoos, A. Al, Mangoosh, A. Al, Miller, S. D., Porter, J. N., Reid, E. A., and Tsay, S. C.: An overview of UAE2 flight operations: Observations of summertime atmospheric thermodynamic and aerosol profiles of the southern Arabian Gulf, J. Geophys. Res., 113, D14213, doi:10.1029/2007JD009435, 2008.

Remer, L. A., Kaufman, Y. J., Tanré, D., Mattoo, S., Chu, D. A., Martins, J. V., Li, R.-R., Ichoku, C., Levy, R. C., Kleidman, R. G., Eck, T. F., Vermote, E., and Holben, B. N.: The MODIS Aerosol Algorithm, Products, and Validation, J. Atmos. Sci., 62, 947-973, 2005.

Remer, L. A., Kleidman, R. G., Levy, R. C., Kaufman, Y. J., Tanré, D., Mattoo, S., Vanderlei Martins, J., Ichoku, C., Koren, I., Hongbin, Y., and Holben, B. N.: Global aerosol climatology from the MODIS satellite sensors, J. Geophys. Res., 113, D14S07, doi:10.1029/2007JD009661., 2008.

Ryder, C. L., Highwood, E. J., Rosenberg, P. D., Trembath, J., Brooke, J. K., Bart, M., Dean, A., Crosier, J., Dorsey, J., Brindley, H., Banks, J., Marsham, J. H., McQuaid, J. B., Sodemann, H., 
and Washington, R.: Optical properties of Saharan dust aerosol and contribution from the coarse mode as measured during the Fennec 2011 aircraft campaign, Atmos. Chem. Phys., 13, 303325, doi:10.5194/acp-13-303-2013, 2013.

Scott, N. A. and Chédin, A.: A fast line-by-line method for atmospheric absorption computations: The Automatized Atmospheric Absorption Atlas. J. Appl. Meteor., 20, 802-812, 1981.

Shao, Y., Wyrwoll, K., Chappell, A., Huang, J., Lin, Z., McTainsh, G. H., Mikami, M., Tanaka, T. Y., Wang, X., and Yoon, S.: Dust cycle: An emerging core theme in Earth system science, Aeol. Res., 2, 181-204, doi:10.1016/j.aeolia.2011.02.001, 2011.

Smirnov, A., Holben, B. N., Dubovik, O., O’Neill, N. T., Eck, T. F., Westphal, D. L., Goroch, A. K., Pietras, C., and Slutsker, I.: Atmospheric Aerosol Optical Properties in the Persian Gulf, J. Atmos. Sci., 59, 620-634, 2002.

Stamnes, K., Tsay, S.-C., Wiscombe, W., and Jayaweera, K.: Numerically stable algorithm for discrete ordinate-method radiative transfer in multiple scattering and emitting layered media, Appl. Optics, 27, 2502-2509, 1988.

Tanré, D., Kaufman, Y. J., Herman, M., and Mattoo, S.: Remote sensing of aerosol properties over oceans using the MODIS/ESO spectral radiances, J. Geophys. Res., 102, 16971-16988, 1997.
Tanré, D., Bréon, F. M., Deuzé, J. L., Dubovik, O., Ducos, F., François, P., Goloub, P., Herman, M., Lifermann, A., and Waquet, F.: Remote sensing of aerosols by using polarized, directional and spectral measurements within the A-Train: the PARASOL mission, Atmos. Meas. Tech., 4, 1383-1395, doi:10.5194/amt-4-1383-2011, 2011.

Tsamalis, C., Chédin, A., and Peyridieu, S.: Daily observation of dust aerosol infrared optical depth and altitude from IASI and AIRS and comparison with other satellite instruments, Geophys. Res. Abstr., 13, EGU2011-6197, 2011.

Tsamalis, C., Chédin, A., Pelon, J., and Capelle, V.: The seasonal vertical distribution of the Saharan Air Layer and its modulation by the wind, Atmos. Chem. Phys. Discuss., 13, 4727-4784, doi:10.5194/acpd-13-4727-2013, 2013.

Winker, D., Hunt, W., and McGill, M.: Initial performance assessment of CALIOP, Geophys. Res. Lett., 34, L19803, doi:10.1029/2007GL030135, 2007.

Winker, D. M., Vaughan, M. A., Omar, A. H., Hu, Y., Powell, K. A., Liu, Z., Hunt, W. H., and Young, S. A.: Overview of the CALIPSO Mission and CALIOP Data Processing Algorithms, J. Atmos. Ocean. Technol., 26, 2310-2323, doi:10.1175/2009JTECHA1281.1, 2009. 